\title{
RESEARCH
}

Open Access

\section{Human mesenchymal stromal cells inhibit platelet activation and aggregation involving CD73-converted adenosine}

\author{
P. Netsch ${ }^{1 \dagger}$, S. Elvers-Hornung ${ }^{1}$, S. Uhlig ${ }^{1,2}$, H. Klüter ${ }^{1}$, V. Huck ${ }^{3,4}$, F. Kirschhöfer ${ }^{5}$, G. Brenner-Weiß ${ }^{5}$, K. Janetzko ${ }^{6}$,
} H. Solz ${ }^{7}$, P. Wuchter ${ }^{1}$, P. Bugert ${ }^{1}$ and K. Bieback ${ }^{1 *+}$ (D)

\begin{abstract}
Background: Mesenchymal stromal cells (MSCs) are promising cell therapy candidates. Clinical application is considered safe. However, minor side effects have included thromboembolism and instant blood-mediated inflammatory reactions suggesting an effect of MSC infusion on hemostasis. Previous studies focusing on plasmatic coagulation as a secondary hemostasis step detected both procoagulatory and anticoagulatory activities of MSCs. We now focus on primary hemostasis and analyzed whether MSCs can promote or inhibit platelet activation.
\end{abstract}

Methods: Effects of MSCs and MSC supernatant on platelet activation and function were studied using flow cytometry and further platelet function analyses. MSCs from bone marrow (BM), lipoaspirate (LA) and cord blood (CB) were compared to human umbilical vein endothelial cells or HeLa tumor cells as inhibitory or activating cells, respectively.

Results: BM-MSCs and LA-MSCs inhibited activation and aggregation of stimulated platelets independent of the agonist used. This inhibitory effect was confirmed in diagnostic point-of-care platelet function analyses in platelet-rich plasma and whole blood. Using inhibitors of the CD39-CD73-adenosine axis, we showed that adenosine produced by CD73 ectonucleotidase activity was largely responsible for the LA-MSC and BM-MSC platelet inhibitory action. With CB-MSCs, batch-dependent responses were obvious, with some batches exerting inhibition and others lacking this effect.

Conclusions: Studies focusing on plasmatic coagulation suggested both procoagulatory and anticoagulatory activities of MSCs. We now show that MSCs can, dependent on their tissue origin, inhibit platelet activation involving adenosine converted from adenosine monophosphate by CD73 ectonucleotidase activity. These data may have strong implications for safety and risk/benefit assessment regarding MSCs from different tissue sources and may help to explain the tissue protective mode of action of MSCs. The adenosinergic pathway emerges as a key mechanism by which MSCs exert hemostatic and immunomodulatory functions.

Keywords: Mesenchymal stromal cells, Platelet activation, CD73, Adenosine, Ectonucleotidase activity, Flow cytometry

\footnotetext{
* Correspondence: karen.bieback@medma.uni-heidelberg.de

${ }^{\dagger} \mathrm{P}$. Netsch and K. Bieback contributed equally to this work.

IInstitute of Transfusion Medicine and Immunology, Medical Faculty

Mannheim, Heidelberg University, German Red Cross Blood Donor Service

Baden-Württemberg-Hessen, Friedrich-Ebert Straße 107, 68167 Mannheim,

Germany

Full list of author information is available at the end of the article
}

(c) The Author(s). 2018 Open Access This article is distributed under the terms of the Creative Commons Attribution 4.0 International License (http://creativecommons.org/licenses/by/4.0/), which permits unrestricted use, distribution, and reproduction in any medium, provided you give appropriate credit to the original author(s) and the source, provide a link to the Creative Commons license, and indicate if changes were made. The Creative Commons Public Domain Dedication waiver (http://creativecommons.org/publicdomain/zero/1.0/) applies to the data made available in this article, unless otherwise stated. 


\section{Background}

Due to their numerous and promising therapeutic capacities, mesenchymal stromal cells (MSCs) are already applied clinically [1]. So far, clinical trials have documented the safety of MSC applications with rare and minor adverse events in humans [2-4]. In animals, however, increased death rates have been observed due to thromboembolic events after infusion [5-9]. Importantly, there has been one report of a patient dying following a pulmonary embolism, potentially related to the MSC application [10].

Thromboembolic events may occur via different mechanisms. First, the relatively large MSCs may be entrapped in and may subsequently occlude small vessels, particularly lung capillaries [7, 9]. This may explain why in animals the cell dose and infusion velocity have been linked to embolic side effects [11]. Second, MSCs may impact hemostasis and actively promote coagulation through high expression of procoagulant molecules like tissue factor (TF), triggering the clotting cascade [6, 12-14]. In consequence, clinical trial protocols have already been modified to add antithrombotics such as heparin or hirudin [12, 13, 15-17]. A recent study suggests selecting for TF-negative MSCs to avoid thromboembolism and IBMIR [14].

With respect to their procoagulant properties, MSCs from different tissue sources seem to differ at both expressional as well as functional levels [14, 18, 19]. In a mouse model, lipoaspirate-derived MSCs (LA-MSCs) were associated with higher risks of embolic events in comparison to bone marrow-derived MSCs (BM-MSCs) [9]. MSCs derived from placental decidua showed increased activation of plasmatic clotting compared to BM-MSCs [13].

In contrast, very few studies have considered the cellular component of thrombosis/hemostasis. Observed effects have varied from increased platelet thrombus formation $[12,15,16]$ to antithrombotic properties in vascular grafts $[20,21]$. We have therefore analyzed the influence of MSCs on platelet activation. We compared MSCs from different tissue sources (BM, LA and cord blood), and evaluated whether conditioned medium or cells stimulate or inhibit the activation of resting or agonist-induced activated platelets. Platelet activation and aggregation was measured using different methods including diagnostic point-of-care techniques.

\section{Methods}

\section{Blood collection and preparation}

Blood was collected with 21-gauge butterfly needles from antecubital veins into citrate phosphate dextrose adenine (CPDA)-containing or hirudin-coated tubes. Donors were volunteer healthy persons giving informed consent, who had not been taking any platelet inhibiting medication for at least 2 weeks.

Platelets were deployed for experiments immediately after collection. Either whole blood or platelet-rich plasma (PRP) was used, obtained by centrifugation of whole blood at $100 \times g$ for $10 \mathrm{~min}$. The PRP was diluted 1:1 with phosphate buffered saline (PBS) before subsequent use.

\section{MSCs, HUVECs and HeLa cells}

Human MSCs from the three different tissue sourcesbone marrow (BM), lipoaspirate (LA) and cord blood (CB) - as well as human umbilical vein endothelial cells (HUVECs) were isolated from multiple different donors and characterized as described previously [22, 23]. Experiments were approved by the Mannheim Ethics Commission II (vote numbers 2010-262 N-MA, 2009-210 N-MA, 49/05 and 48/05). HeLa tumor cells were kindly provided by Prof. Ilse Hofmann, DKFZ, Heidelberg, Germany. HUVECs and HeLa tumor cells served as controls; endothelial cells have been shown to inhibit and tumor cells to promote platelet activation [24, 25].

All cells were stored cryopreserved in fetal bovine serum (FBS)/10\% DMSO and were then thawed and cultivated for at least one passage before use. HUVECs were cultured in EGM-2 (Lonza, Basel, Switzerland), and MSCs and HeLa cells in DMEM (Lonza) supplemented with 10\% FBS (PromoCell, Heidelberg, Germany), $4 \mathrm{mM}$ glutamine and antibiotics. To standardize conditions for MSCs, HUVECs and HeLa cells, respectively, cells were seeded at a defined density in T175 flasks 2 days before performing the experiments: MSCs at $1 \times 10^{6}$ cells, passages 3-4 (to test for replicative aging also until passage 6); HUVECs at $2 \times 10^{6}$ cells, passages $3-5$; and HeLa cells at $5 \times 10^{6}$ cells. Immediately before the experiments, the cells were detached with trypsin-EDTA, washed, counted and resuspended in PBS. The cell doses $\left(10^{5}, 5 \times 10^{5}\right.$, $2.5 \times 10^{6}$ cells $/ \mathrm{ml}$ ) employed for our study were calculated according to the cell numbers applied clinically [1]. Conditioned medium (CM) was collected $48 \mathrm{~h}$ after seeding $10^{6}$ cells in T175 flasks. Pure culture medium served as a control.

\section{Flow cytometry}

Flow cytometry was performed on a BD FACSCanto ${ }^{\mathrm{mm}}$ II (Becton Dickinson, Heidelberg, Germany). Data were obtained with BD FACS Diva software and analyzed with FlowJo software (FlowJo, LLC, Ashland, OR, USA).

Before stimulation, platelets were incubated at room temperature with respective cells or $\mathrm{CM}$ for $10 \mathrm{~min}$ in the presence of the staining antibodies. Following this, platelets were activated with TRAP- 6 (protease-activated receptor 1 (PAR-1) agonist), ADP (P2Y1, P2Y12 and 
P2X1 receptor agonist) or U46619 (thromboxane A2 (TP) receptor agonist) (all $5 \mu \mathrm{M}$; Roche, Mannheim, Germany) for $10 \mathrm{~min}$. Experiments were performed at staggered times or samples were fixed directly after the stimulation period by $0.5 \%$ paraformaldehyde and then analyzed.

Platelets were stained with an antibody panel including the activation-dependent markers PAC-1-FITC (activated GPIIb/IIIa (CD41/CD61) complex, clone PAC-1; Becton Dickinson), CD62P-APC (P-selectin, clone AK-4; Becton Dickinson) and CD63-PE-Cy7 (LAMP-3, clone H5C6; Becton Dickinson) and the platelet-specific surface marker CD41-PE (IIb subunit of GPIIb/IIIa complex, clone HIP8; Beckman Coulter, Krefeld, Germany) [26]. Antibodies had been titrated. A platelet gate was set according to FSC-PE and at least 10,000 events were recorded.

To quantify the respective receptor expression by flow cytometry, cells were stained with anti-CD73 (PE, clone AD-2; Becton Dickinson), anti-CD39 (PerCP-Cy5.5, clone TU66; Becton Dickinson) and anti-adenosine A2A receptor (A2AR, 7F6-G5-A2 Alexa Fluor 488; Santa Cruz Biotechnology, Heidelberg, Germany).

\section{Inhibitors}

Different mechanisms have been shown to interfere with platelet activation. To understand which is affected by MSCs, we used different inhibitors, as specified in the following [27-29].

CD62P was blocked by the mouse anti-human antibody AK-4 (eBioscience, ThermoFisher, San Diego, CA, USA). PRP $50 \mu \mathrm{l}$ was preincubated with $1 \mu \mathrm{g}$ AK-4 or the respective isotype control for $20 \mathrm{~min}$ before adding the MSCs.

For COX inhibition, MSCs were cultured with indomethacin (10 $\mu \mathrm{M}$; Sigma Aldrich) for 2 days. Two hours before the experiments the medium was changed and fresh indomethacin added to the coculture.

CD39 was inhibited by the antagonist sodium polyoxotungstate (100 and $10 \mu \mathrm{M}$ POM-1; Tocris, Wiesbaden-Nordenstadt, Germany), CD73 inhibited by AMP-CP $(100 \mu \mathrm{M} \quad \alpha, \beta$-methyleneadenosine 5 '-diphosphate; Santa Cruz), adenosine receptors inhibited by caffeine (200 $\mu \mathrm{M}$; Santa Cruz) and A2A adenosine receptor was inhibited by $25 \mu \mathrm{M} \mathrm{SCH} 58261$ (Tocris, $25 \mathrm{mM}$ stock in DMSO, DMSO used as control). Alkaline phosphatase (ALP) was inhibited by levamisole hydrochloride $(100 \mu \mathrm{M}$; Abcam, Cambridge, UK). Adenosine deaminase (ADA) from calf intestine $(2.55 \mathrm{U} / \mathrm{ml}$; Sigma Aldrich) was added to deaminate adenosine [30, 31]. All inhibitors were preincubated for $10 \mathrm{~min}$ with MSCs before adding PRP. Adenosine $(1 \mu \mathrm{M}$; Santa Cruz) was used as positive control. For most inhibitors, different dilutions have been tested to identify the working concentration.

\section{Detection of ectonucleotidase activity}

Ectonucleotidase activity was measured in the cells as described previously [32]. Briefly, cells were seeded at $10,000 \mathrm{cells} / \mathrm{cm}^{2}$ in 24-well plates and then incubated for $24 \mathrm{~h}$. ATP, ADP and AMP (1 mM; Santa Cruz) were then added in phosphate-free buffer and incubated for either $1 \mathrm{~h}$ (ATP and ADP) or $30 \mathrm{~min}$ (AMP). Supernatant was harvested for protein quantification (BCA assay; Thermo Fisher, Waltham, MA, USA), inorganic phosphate quantification (malachite green assay kit, according to the manufacturer's instructions; Sigma Aldrich) or adenosine detection.

\section{Quantitative determination of adenosine by LC-MS/MS}

The samples were separated by HPLC (Agilent 1100, Waldbronn, Germany) using a LiChrospher 100 RP C-18, $5 \mu \mathrm{m}$ column $(125 \mathrm{~mm} \times 4 \mathrm{~mm})$ in combination with a gradient method of acetonitrile and $0.1 \%$ acetic acid at a flow rate of $500 \mu \mathrm{l} / \mathrm{min}$. Mass spectrometric analysis was carried out using an API $4000^{\mathrm{max}}$ quadrupole mass spectrometer (Applied Biosystems/MDS Sciex, Toronto, Canada) equipped with an electrospray ionization (ESI) source in the positive mode. MS/MS infusion experiments were performed to determine the specific mass transitions of adenosine (quantifier $\mathrm{m} / \mathrm{z} 268$ to $\mathrm{m} / \mathrm{z}$ 136, qualifiers m/z 268 to $\mathrm{m} / \mathrm{z} 119$ and $\mathrm{m} / \mathrm{z} 268$ to $\mathrm{m} / \mathrm{z}$ 92) for multiple reaction monitoring (MRM) analysis. All quantitative analyses were carried out using a sample volume of $10 \mu \mathrm{l}$ containing adenosine-d5 as internal standard. The adenosine content of the samples was determined by a standard calibration function in the required concentration range.

\section{Alkaline phosphatase and adenosine deaminase activity measurement}

Both enzymatic activities were measured in cell lysates with defined cell numbers by fluorometric assay kits according to the manufacturer's instructions (ALP assay kit ab83371 and ADA assay kit ab204695; both Abcam).

\section{Vasodilator-stimulated phosphoprotein phosphorylation state}

The phosphorylation state of vasodilator-stimulated phosphoprotein (VASP), indicative for cyclic nucleotide levels in platelets, was measured using cytometric bead technology (VASPFix; Platelet Solutions, Nottingham, UK) [33]. Briefly, PRP was coincubated for $10 \mathrm{~min}$ with $10 \mu \mathrm{M}$ adenosine or $5 \times 10^{5}$ cells $/ \mathrm{ml}$, followed by addition of ADP $(5 \mu \mathrm{M})$. After $5 \mathrm{~min}$, $5 \mu \mathrm{l}$ of the platelet suspension was mixed with $25 \mu \mathrm{l}$ of VASPFix reagent, vortexed and incubated for $2 \mathrm{~h}$. The VASP phosphorylation state was assessed by flow cytometry using an APC (bead) and FITC (VASP-P) 
dot-plot gate, assessing the change in VASP-P-FITC mean fluorescence intensity (MFI).

\section{Platelet function analyzer}

Platelet adhesion, activation and aggregation were assessed in a system simulating the in-vivo hemodynamics in the small capillaries (PFA-100; Siemens Healthcare Diagnostics, Eschborn, Germany). Citrated whole blood was aspirated at high shear rates though a small aperture coated with collagen and ADP. The gradual occlusion of the aperture by adhering platelets was measured as the closure time. Briefly, $900 \mu \mathrm{l}$ of citrate-anticoagulated whole blood (platelet count $>150,000 / \mu \mathrm{l}$ and hematocrit $>35 \%$ ) was mixed with either $10 \mu \mathrm{M}$ adenosine or $5 \times 10^{5}$ cells $/ \mathrm{ml}$ and incubated for $10 \mathrm{~min}$. The whole blood suspension $(800 \mu \mathrm{l})$ was added to the analysis cuvettes, the $\mathrm{ADP} /$ collagen measurement was started and the closure time recorded.

\section{Light transmission aggregometry}

The rate and extent of platelet activation, aggregation and agglutination was measured by light transmission aggregometry. PRP was stirred in a cuvette at $37^{\circ} \mathrm{C}$ and photometrically monitored. Agonist-induced activation and aggregation induces a change from light absorbance to increased transmission (Platelet Aggregation Profiler", Model PAP-8E; MöLab GmbH, Langenfeld, Germany). Briefly, PRP was prepared by centrifugation at $150 \times g$ for $10 \mathrm{~min}$ and then carefully removed. The remaining blood was centrifuged at $2700 \times g$ for $15 \mathrm{~min}$ to obtain platelet-poor plasma (PPP). The PPP was used to calibrate the system to $100 \%$ light transmission. Measurements were made on $250 \mu \mathrm{l}$ aliquots of PRP preincubated for $10 \mathrm{~min}$ with $10 \mu \mathrm{M}$ adenosine or with $5 \times 10^{5}$ cells $/ \mathrm{ml}$ at $37{ }^{\circ} \mathrm{C}$ in the aggregometry cuvette, after addition of $5 \mu \mathrm{M}$ ADP.

\section{Real-time quantitative PCR}

Real-time quantitative PCR (RT-qPCR) of procoagulant and anticoagulant factors was performed as described previously [34]. The RNeasy Mini Kit (Qiagen, Hilden, Germany) was used for mRNA isolation, the Transcriptor High Fidelity cDNA Synthesis Kit (Roche Diagnostics, Mannheim, Germany) for cDNA transcription and the SensiFast $^{\text {tu }}$ Probe No-ROX Kit (Bioline, Luckenwalde, Germany) for PCR. The intron-spanning primers and probes (Universal Probe Library, Roche, Mannheim, Germany) presented in Additional file 1: Table S1 were used with a Light Cycler 480 (Roche). Relative quantification was performed using the E-method with GAPDH and SFRS4 as reference genes. The efficiency of all primers was in the range of 1.9-2.2.

\section{Statistical analysis}

For statistical analysis, the degree of platelet activation was quantified by the mean fluorescence intensity (MFI) using flow cytometry. For some experiments, data were normalized to the respective control without cells/stimulator/inhibitor added. Significance testing was performed using a paired $t$ test, repeated-measures one-way ANOVA, one-way or two-way ANOVA followed by Holmes-Sidak or Dunnett's test or the Kruskal-Wallis test for nonparametric data (Sigma Plot 11.0; Systat Software, San Jose, CA, USA; and GraphPad Prism 7; GraphPad Software, La Jolla, USA).

\section{Results \\ MSC conditioned medium does not affect platelet activation}

To see whether MSCs produce any soluble factors influencing platelet activation, we quantified activation marker expression on resting (w/o agonist) and ADP or TRAP-6-stimulated platelets. There was no effect of any culture medium $(\mathrm{CM})$ on resting platelets (data not shown). On agonist-stimulated platelets, there was also no effect of CM on BM-MSCs and LA-MSCs, independent of the added dose of 2.5-10\% (Fig. 1). Low concentrations of CB-MSC CM suppressed the activation of platelets $(0.40 \pm 0.034$ for CD62p and $0.61 \pm 0.036$ for PAC- 1 at $2.5 \%$ CM compared to the control set to 1 ), but higher concentrations did not suppress compared to the control $(10 \% \mathrm{CM}, 1.30 \pm 0.23$ for CD62p and $1.18 \pm 0.19$ for PAC-1; significant differences between 2.5 and $10 \%$ CM). HUVEC CM had no effect on platelet activation $(1.05 \pm 0.04$ for CD62p and $0.96 \pm 0.04$ for PAC- 1 at $10 \%$ $\mathrm{CM})$. HeLa CM, however, increased the agonist-induced activation of platelets dose dependently (from 0.89-fold at $2.5 \%$ CM to 4.05 -fold at 10\% CM for CD62p).

\section{MSCs inhibit agonist-induced platelet activation}

Having observed that CM does not affect platelet activation, we then assessed the effect in cell-platelet cocultures. When platelets were agonist stimulated, all MSCs reduced the degree of platelet activation. All activation markers assessed were similarly affected (Fig. 2a). For CB-MSCs, however, donor-specific batch variation was apparent, with some batches even increasing platelet activation. HUVECs, as expected, reduced platelet activation, while HeLa cells had no significant effect. Next, we tested different MSC concentrations in the range of the concentrations employed in clinical treatments $\left(10^{5}, 5 \times 10^{5}, 2.5 \times 10^{6}\right.$ cells $\left./ \mathrm{ml}\right)$. There was a clear dose-dependent effect of BM-MSCs (Fig. 2c for CD62p; other markers not shown). Interestingly, for LA-MSCs this was not apparent and with higher CB-MSC numbers the inhibitory effect was reduced, similar to the CM. HUVECs caused the expected dose-dependent 


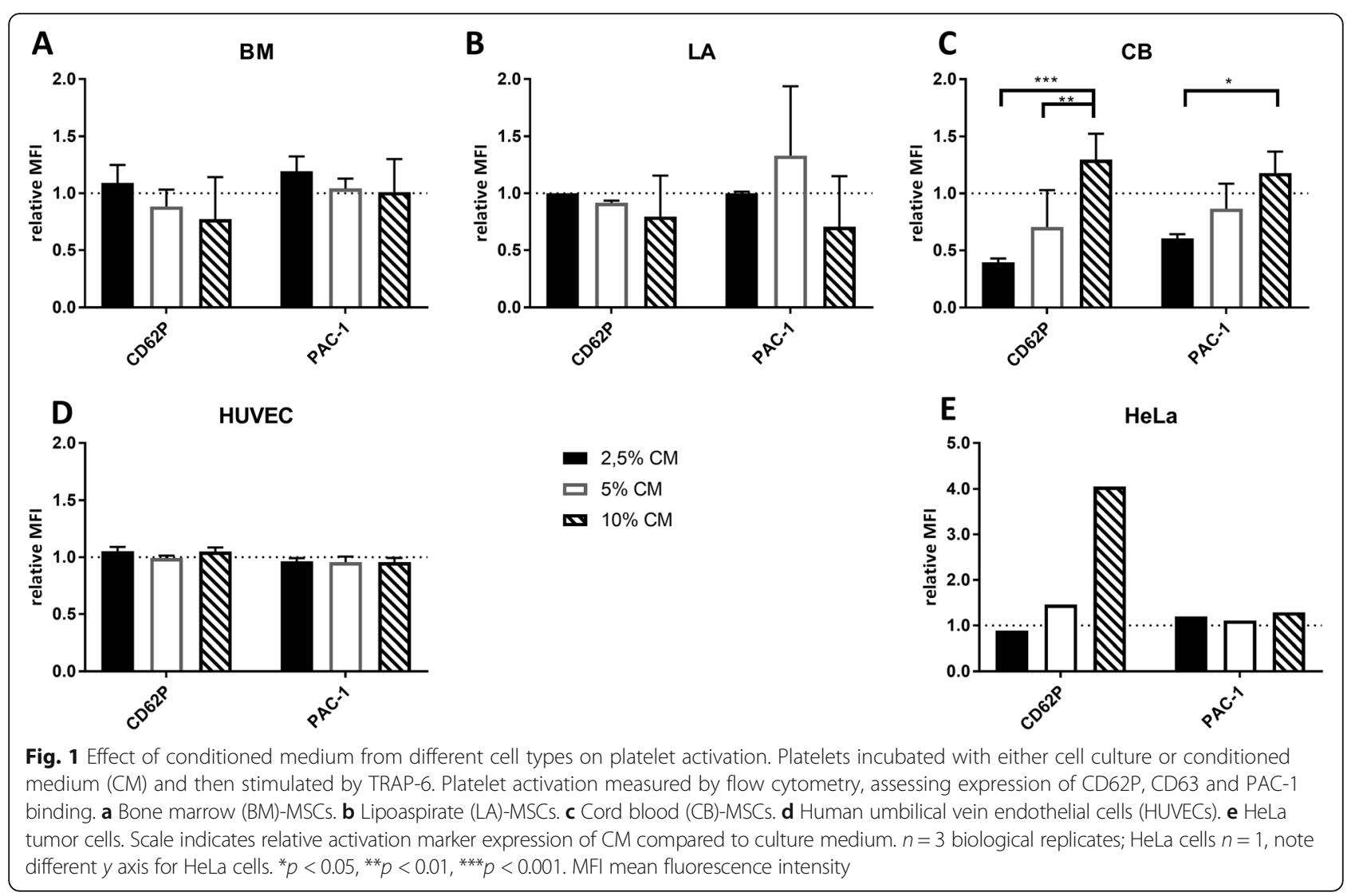

inhibition, while HeLa cells had no significant effect at any concentration.

Next, we checked whether the MSCs activate resting platelets. BM-MSCs, LA-MSCs and HUVECs did not activate resting platelets (Fig. 2b, d). Interestingly, $2.5 \times$ $10^{6} \mathrm{CB}-\mathrm{MSCs} / \mathrm{ml}$ led to a 5-fold increase in CD62P expression and an 11-fold increase in PAC-1 binding, comparable to HeLa cells.

We verified that the inhibitory effect was donor specific and not affected by cellular aging (passages 3-6; data not shown), as reported for other MSC properties [35]. Different culture supplements used to expand MSCs (FBS, human AB serum or human platelet lysate) did not affect the inhibitory capacity of either BM-MSCs or LA-MSCs (data not shown) [36].

Additional experiments were performed: under shear-flow conditions, BM-MSCs likewise appeared to reduce the number of platelet aggregates formed on fibronectin (Additional file 2: Figure S1); using impedance aggregometry in whole blood, all cell types reduced platelet aggregation (multiplate device, Additional file 3: Figure S2); and potential platelet binding to MSCs was assessed by microscopy and flow cytometry. TRAP-6-stimulated platelets formed thrombi. HeLa cells and also CB-MSCs induced aggregation of activated and resting platelets (Additional file 4: Figure
S3A-I, $p=0.004$ for unstimulated vs stimulated platelets and $p=0.02$ for unstimulated platelets vs stimulated platelets + HeLa cells), whereas BM-MSCs prevented stimulus-induced platelet aggregation (Additional file 4: Figure S3I). No platelet binding to any of the cells was apparent using flow cytometry, assessed by gating on MSC FSC/SSC and then calculating for CD41 positivity (Fig. 3J, no variance between cells w/o platelets and with unstimulated or stimulated platelets comparing $n=3$ biological replicates for MSC and HUVECs, respectively).

\section{MSCs inhibit platelet activation independent of the activation pathway, P-selectin and cyclooxygenase} The fact that BM-MSCs and LA-MSCs significantly reduced platelet activation prompted the question of whether specific activation pathways are affected. Using flow cytometry, we measured three individual activation markers, CD62p, PAC-1 and CD63, plus three different platelet agonists, TRAP-6 (chosen for all subsequent analyses), ADP and U46619. Inhibition was apparent independent of the anticoagulant (data not shown) and for all three activation-dependent markers and agonists (Figs. 1 and 2, Additional file 5: Figure SA, B). Based on these data we conclude that the MSC-mediated effect is not directly linked to a specific pathway but interferes with platelet activation globally. 


\section{A Effect on platelet activation}
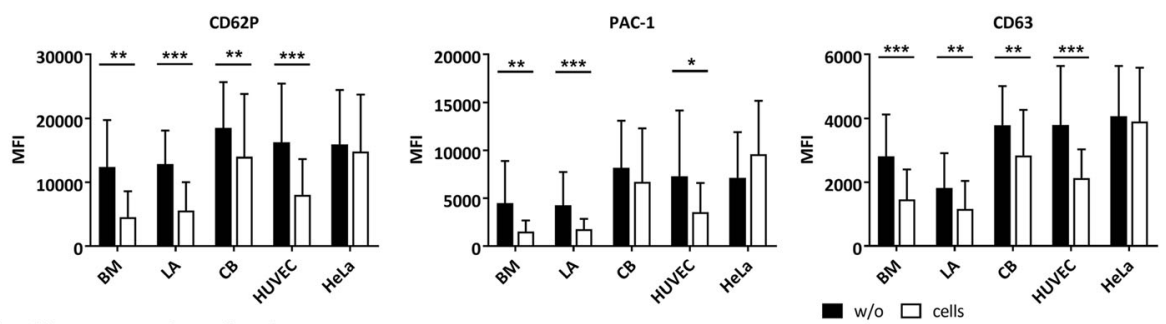

B Effect on resting platelets
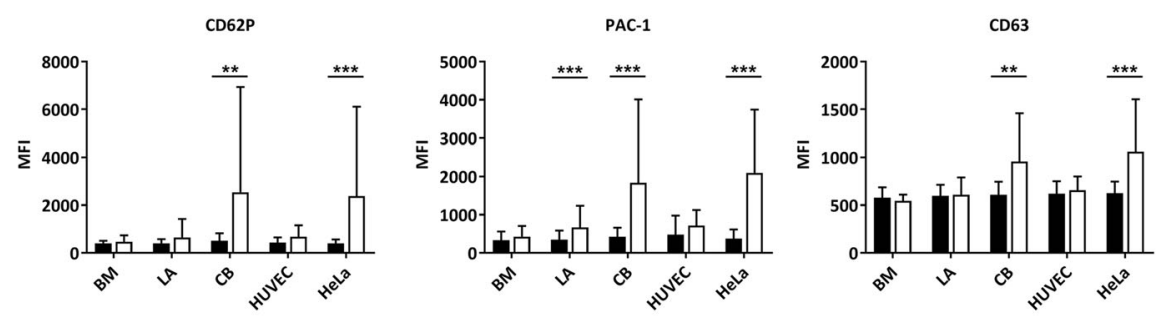

C Dose effect on platelet activation

D Dose effect on resting platelets
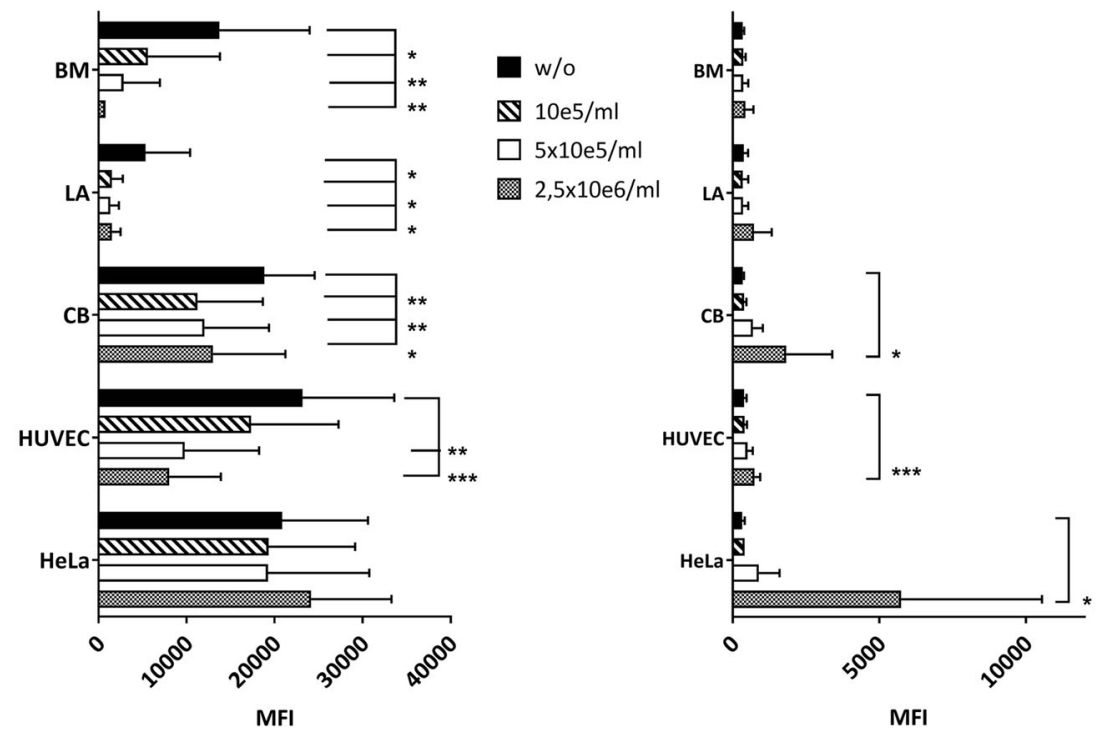

Fig. 2 Effect of different cell types and dosages on platelet activation and resting platelets in flow cytometry. Platelets incubated with or without (w/o) indicated cell types. Then platelets either activated by TRAP-6 or remained resting. $\mathbf{a}$, $\mathbf{b}$ Influence of $5 \times 10^{5}$ cells/ml on a TRAP-6-induced platelet activation and $\mathbf{b}$ resting platelets. Mean fluorescence intensity (MFI) of different thrombocyte activation markers assessed: CD62P, PAC-1 binding and CD63 $(n=8-17)$. c, $\mathbf{d}$ Dose effect of different cell types on CD62P detection on c TRAP-6-stimulated platelets and $\mathbf{d}$ resting platelets $(n=5-6)$. Different MFI values of platelets explained by different platelet donors used in individual experiments. In all experiments, paired analysis against control w/o cells was performed. ${ }^{*} p<0.05,{ }^{* *} p<0.01,{ }^{* * *} p<0.001$. BM bone marrow, CB cord blood, HUVEC human umbilical vein endothelial cell, LA lipoaspirate

Endothelial progenitor cells have been shown to suppress platelet activation via CD62p and COX [27, 28]. However, neither the CD62P blocking antibody AK4 nor the nonselective COX inhibitor indomethacin were capable of neutralizing the MSC inhibitory activity (Additional file 5: Figure S4C, D), although MSCs express Cox-2 mRNA at highly differing levels (data not shown).
CD73-converted adenosine is involved in MSC platelet inhibitory activity

We postulated that adenosine converted by CD73 ectonucleotidase activity may be responsible for the platelet inhibition. Adenosine has been shown previously to be inhibitory in endothelial-platelet interactions, and to contribute to MSC immunomodulatory activity [29, 37-40]. Extracellular ATP metabolism provides the prothrombotic 


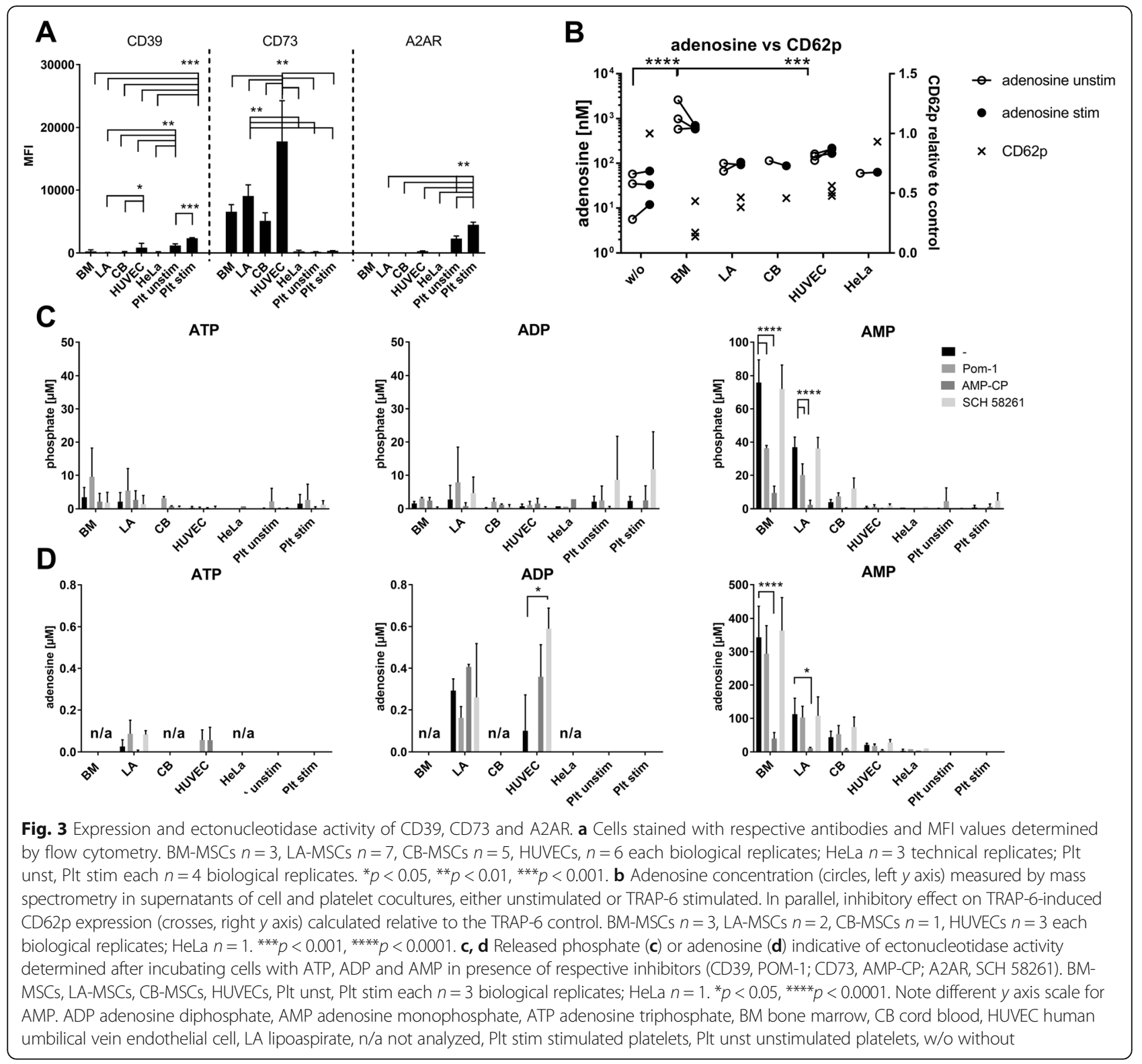

ligands ATP and ADP (released from dense granula upon platelet activation and hydrolyzed by CD39) and the antithrombotic AMP and adenosine (by CD73 activity) detected by $\mathrm{P} 1$ adenosine receptors (on platelets provides mainly adenosine $\mathrm{A} 2$ receptor (A2AR)) [29, 41].

We first checked CD39, CD73 and A2AR expression. Platelets expressed both CD39 and A2AR at high MFI values, whereas CD73 was only dimly expressed (Fig. 3a). In MSCs, in contrast, CD73 was highly expressed, but CD39 and A2AR only dimly. HUVECs had the highest CD73 reactivity, with low CD39 and A2AR expression.

To test our hypothesis, we measured platelet activation and in parallel the adenosine concentration in MSCplatelet cocultures (Fig. 3b). In the presence of MSCs and HUVECs, adenosine levels were increased irrespective of
TRAP-6 stimulation. HUVECs, despite a higher CD73 expression, had adenosine levels only slightly higher than LA-MSCs and CB-MSCs, with comparable antithrombotic activity. BM-MSCs, which showed the highest adenosine concentrations, exerted the highest inhibitory activity on platelet activation. These data support our hypothesis that MSC-generated adenosine conferred antithrombotic activities. In fact, the concentrations measured in cocultures were exactly in the range of the inhibitory adenosine concentration, strongest at $10-0.01 \mu \mathrm{M}$ adenosine for both PRP and whole blood (see Fig. 6a).

To quantify the activity of CD39 and CD73, cells were incubated with ATP, ADP and AMP and with inhibitors of the nucleotide degradation cascade (POM-1 for CD39, AMP-CP for CD73 and SCH 58261 for A2AR). 
The released phosphate and adenosine was measured. ATP and ADP generated only minor amounts of phosphate and adenosine, indicating very low ATP/ADP degradative properties. However, MSCs were able to catabolize AMP to phosphate and adenosine (Fig. 3b, c), significantly inhibited by AMP-CP, indicating that CD73 activity is crucial for AMP conversion. Despite the high expression of CD73 in HUVECs, they showed little phosphate and adenosine production. In BM-MSCs and LA-MSCs, POM-1 significantly inhibited phosphate, but not adenosine generation, suggesting a minor involvement of CD39. Platelets per se, neither unstimulated nor stimulated, produced detectable amounts of adenosine.

To verify that CD73-converted adenosine regulates platelet reactivity, we added the aforementioned inhibitors to MSC-platelet cocultures. POM-1 (both 100 and $10 \mu \mathrm{M})$ significantly reduced TRAP-induced platelet activation (Fig. 4a; ADP and U46619 not shown), supporting our notion that CD73-mediated adenosine generation causes platelet inhibition (Fig. 4b) [42]. AMP-CP and SCH 58261 had no effect on platelet activation per se. POM-1 did not counteract the MSC-mediated antithrombotic activity. The CD73 inhibitor AMP-CP, however, significantly antagonized the inhibitory effect of BM-MSCs, LA-MSCs and HUVECs, supporting our notion that CD73-mediated adenosine generation causes platelet inhibition (Fig. 4c-f). In CB-MSCs, again, data varied with different cell batches. The adenosine receptor inhibitors, SCH 58261 specific for A2AR and nonspecific P1 receptor inhibitor caffeine, partially reversed the inhibitory effects of BM-MSCs and LA-MSCs, demonstrating that adenosine sensed by adenosine receptors converts the inhibitory signal. The facts that caffeine exerted a stronger effect in reducing MSC inhibition while SCH 58261 strongly reduced the inhibitory activity of adenosine suggest that A2AR is the main adenosine receptor on platelets, but that in MSCplatelet cocultures other P1 receptors are predominant, probably expressed on MSCs [43]. These findings indicate that the CD73-adenosine axis is a key mechanism in platelet inhibition by MSCs. It was striking that PAC-1 expression was strongly increased in the presence of the inhibitors exceeding the expression level of stimulated platelets (set to 1). This suggests that when the inhibitory adenosine action is inhibited, MSCs can accelerate induced platelet activation acting on specific pathways.

For HUVECs and BM-MSCs there was a large discrepancy between CD73 expression intensity and enzymatic activity, suggesting that other factors are involved or that CD73 expression does not correlate to enzymatic activity. Alkaline phosphatase (ALP) can act synergistically to CD73 to metabolize AMP to adenosine [31]. Adenosine deaminase (ADA) activity converts adenosine to inosine, stopping the inhibitory action of adenosine [30]. HeLa cells showed high ALP activity (Fig. 5a). BM-MSCs exerted a highly batch-dependent ALP activity, while the ALP activity of LA-MSCs, CB-MSCs and HUVECs was low. ADA activity was comparable for all samples, except for LA-MSCs where two out of the three donors showed high ADA activity. To test for their effects in MSC-platelet cocultures, we added the ALP inhibitor levamisole and ADA. Levamisole at a concentration of $1 \mathrm{mM}$ inhibited platelet activation per se, similar to POM-1. At $100 \mu \mathrm{M}$ this inhibitory effect was negligible (Fig. 5c). Levamisole slightly, but not significantly, reduced the inhibitory effect of all MSCs and HUVECs. Externally added ADA ameliorated the adenosine action and significantly reduced the inhibitory effect of LA-MSCs, probably adding on the ADA activity of LA-MSCs to achieve adenosine neutralization.

\section{Verification using additional platelet function analyses}

To document that MSCs triggered adenosine signaling in platelets, and that the suppressive strength was relevant not only in PRP but also in whole blood, we performed further platelet function tests including point-of-care technologies.

First, we checked the concentration range of adenosine in PRP and whole blood. In fact, adenosine concentrations obtained in MSC-platelet cocultures were in the inhibitory range of adenosine in both PRP and whole blood (Fig. 6a).

Second, the phosphorylation state of vasodilator-stimulated phosphoprotein (VASP) was assessed in ADP-stimulated PRP. VASP-P levels are indicative of cAMP levels, known as master switches of platelet activation and aggregation [33, 41]. Adenosine activates adenylate cyclase, increasing cAMP levels and VASP phosphorylation, thus inhibiting platelet aggregation [44]. Indeed, adenosine increased the MFI of VASP-P, further raised by ADP stimulation (Fig. 6b). Without ADP stimulation, MSCs and HUVECs led to a slight increase and to a further rise upon ADP stimulation that was significant for BM-MSCs. CB-MSCs clearly split into two clusters, one inducing little VASP-P elevation after ADP addition while the other promoted VASP-P levels similar to BM-MSCs. HeLa cells did not influence VASP-P. These data support that MSCs induce the same signaling events as adenosine.

Third, we analyzed the MSC effects on platelet adhesion, activation and aggregation in whole blood using the platelet function analyzer (PFA-100), a well-established diagnostic point-of-care test [45]. As expected, adenosine prolonged the time needed to form a platelet plug closing an aperture (Fig. 6c). BM-MSCs, LA-MSCs and HUVECs likewise delayed platelet function, while CB-MSCs exerted a minor effect. HeLa cells repeatedly caused an error in the measurement. 


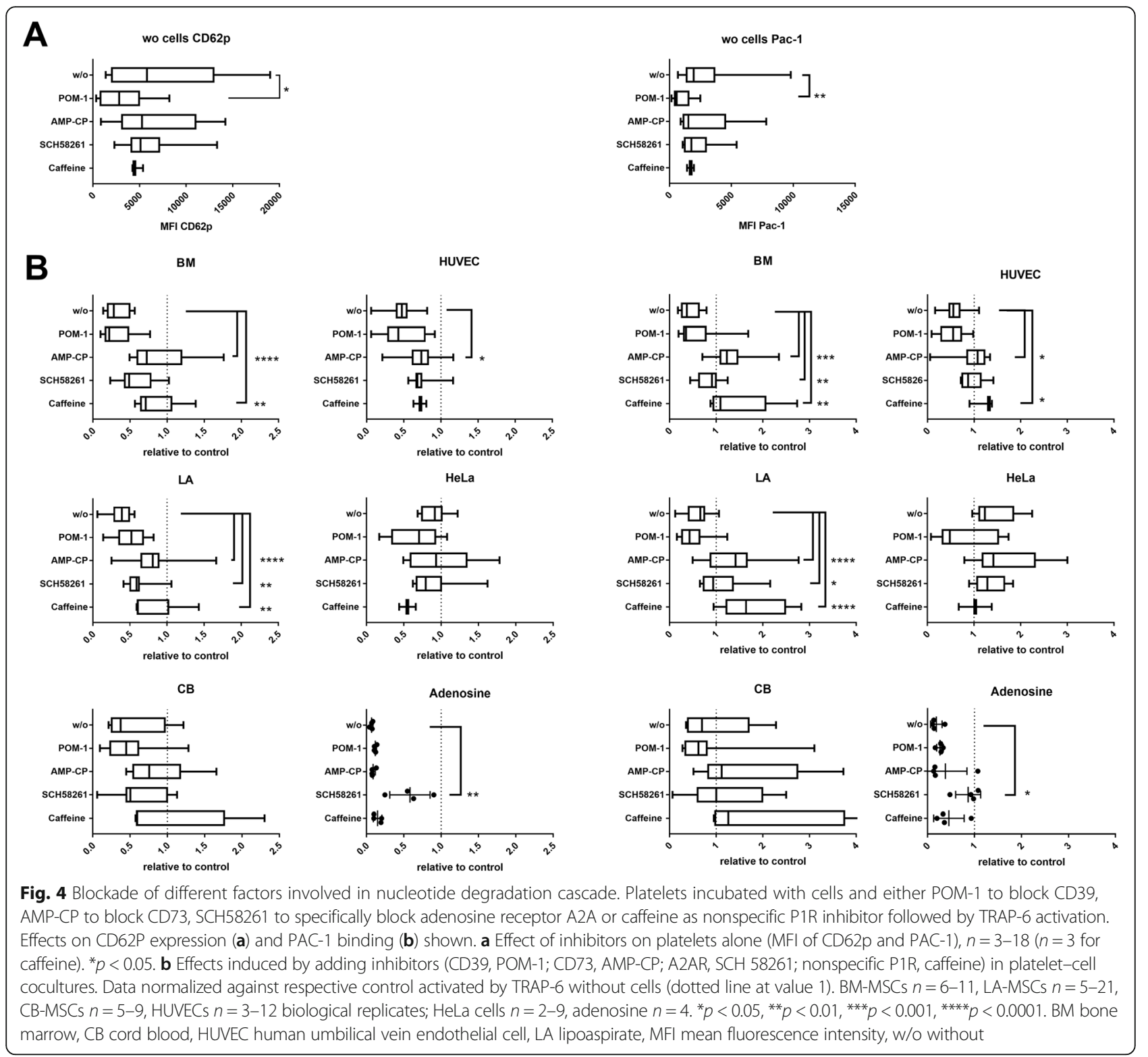

Fourth, we used light transmission aggregometry (platelet aggregation profiler, PAP 8E), which distinguishes between the different stages of platelet activation: primary aggregation induced by the added agonist; secondary aggregation induced by endogenous agonists; and maximal and final aggregation which may differ when disintegration of platelet aggregates occurs. The speed of aggregation is measured as a primary slope. Area under the curve (AUC) values reflect the entire reaction cascade. Upon ADP stimulation, adenosine reduced the primary aggregation response, the speed and also the final aggregation compared to the control (Fig. 6d). The effects of BM-MSCs and LA-MSCs were similar. CB-MSCs and HUVECs exerted less pronounced platelet inhibition. HeLa cells $(n=1)$ showed a similar pattern, possibly related to the platelet donor (slight inhibitory activity was seen in the corresponding flow cytometry experiments). Despite the low sample number, AUC values indicated statistically significant differences of adenosine; all MSCs and HUVECs reduced platelet aggregation. In conclusion, all performed platelet function analyses confirmed the inhibitory effect of at least BM-MSCs and LA-MSCs on platelet function to a similar extent as adenosine.

\section{Gene expression of procoagulant and anticoagulant factors}

In the present study, we identified CD73-generated adenosine as the major mechanism by which MSCs inhibit platelet activation. Hemostasis, however, involves at least three 

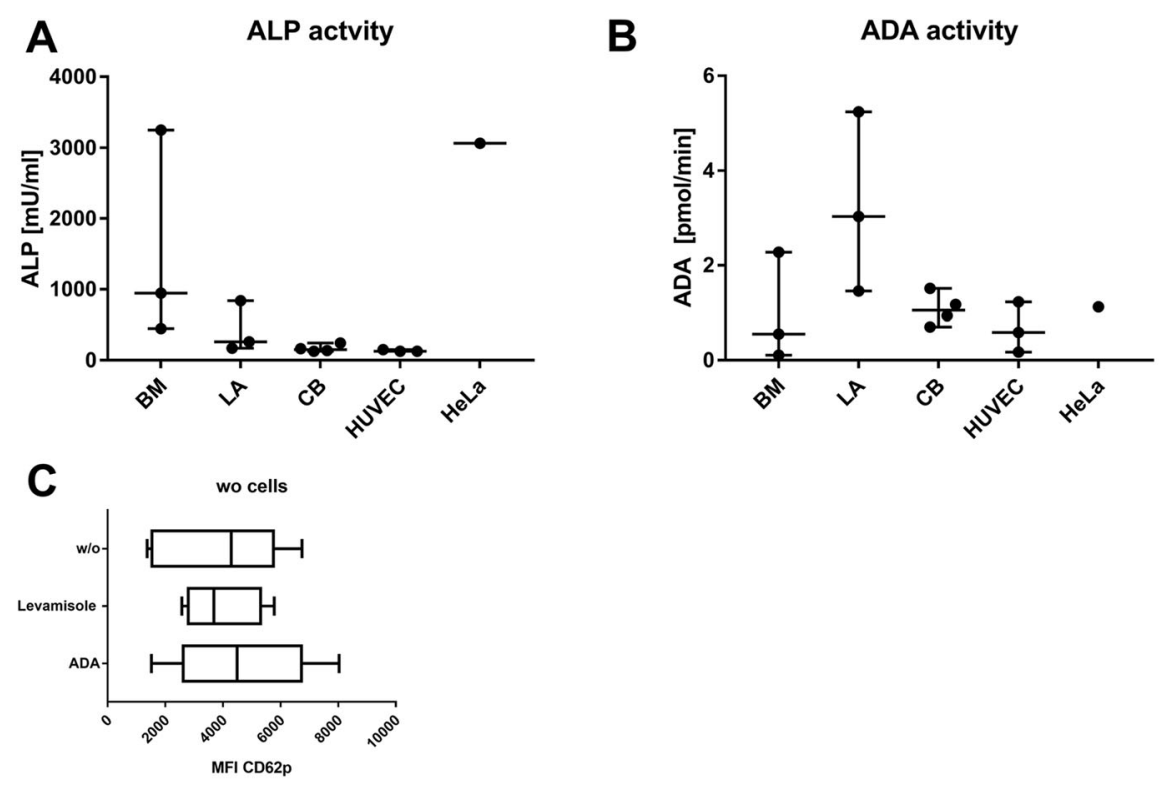

BM

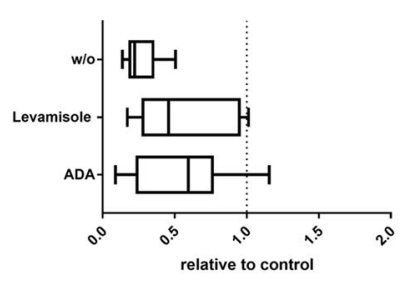

HUVEC

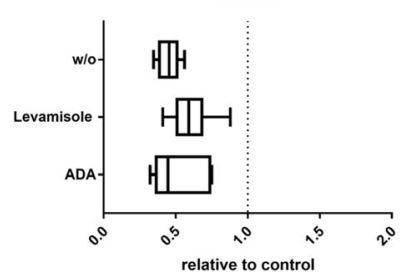

LA

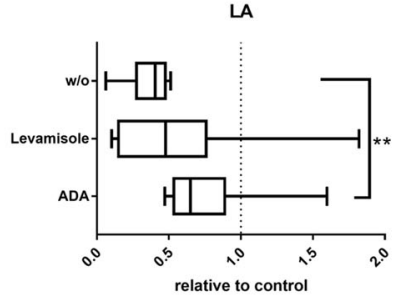

HeLa

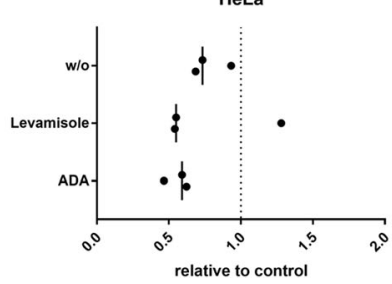

CB

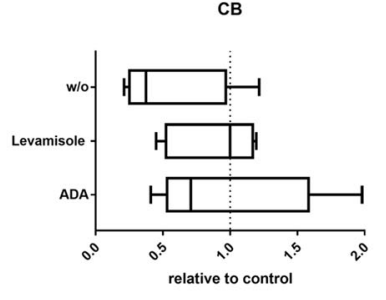

Adenosine

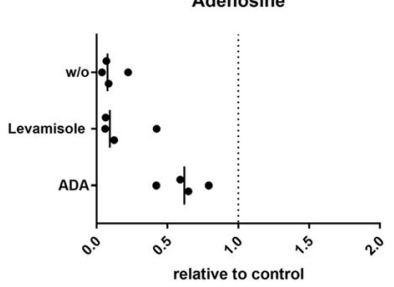

Fig. 5 Alkaline phosphatase and adenosine deaminase activity and function blocking. a Alkaline phosphatase (ALP) and $\mathbf{b}$ adenosine deaminase (ADA) activity in different cell types. Individual biological replicates depicted as dots. c Effects induced by adding ALP inhibitor levamisole or ADA in platelet-cell cocultures. Data normalized against control activated by TRAP-6 without cells (dotted line at value 1). W/O $n=4-11$, BM-MSCs $n=9$, LA-MSCS $n=7-12$, CB-MSCs $n=5-9$, HUVECs $n=6$ biological replicates; HeLa cells $n=3$, adenosine $n=4$. ${ }^{*} p<0.01$. BM bone marrow, CB cord blood, HUVEC human umbilical vein endothelial cell, LA lipoaspirate, MFI mean fluorescence intensity, w/o without

steps: vasoconstriction, platelet activation/plug formation and coagulation. To estimate the potential involvement in the coagulation cascade and to compare with previously published data $[6,12-14,16,19]$, we finally assessed the gene expression of different procoagulatory and anticoagulatory genes. Comparing MSCs to endothelial cellsHUVECs and cord blood-derived endothelial colony forming cells (CB-ECFC) [22] - no differences were observable, except for TF expression that was apparently higher in all MSCs (Fig. 7). CB-MSCs compared to CB-ECFCs had a reduced expression of plasminogen- activator inhibitor (PAI). Thus, we conclude that the observed source-specific differences in platelet reactivity are based on the identified adenosine metabolism rather than on coagulation.

\section{Discussion}

With respect to the safety of MSC infusion, our paper combines a translationally relevant issue with an important basic research question about the underlying mechanism. Focusing on the effect of MSCs on platelet function, we document that BM-MSCs and LA-MSCs, and with batch variations also CB-MSCs, inhibited the agonist-induced activation and aggregation of platelets-even more than endothelial cells, well known to regulate platelet reactivity. This inhibitory activity was confirmed to happen in both PRP and whole blood by applying a variety of platelet function tests including point-of-care diagnostic tests, underlining the physiological relevance. 

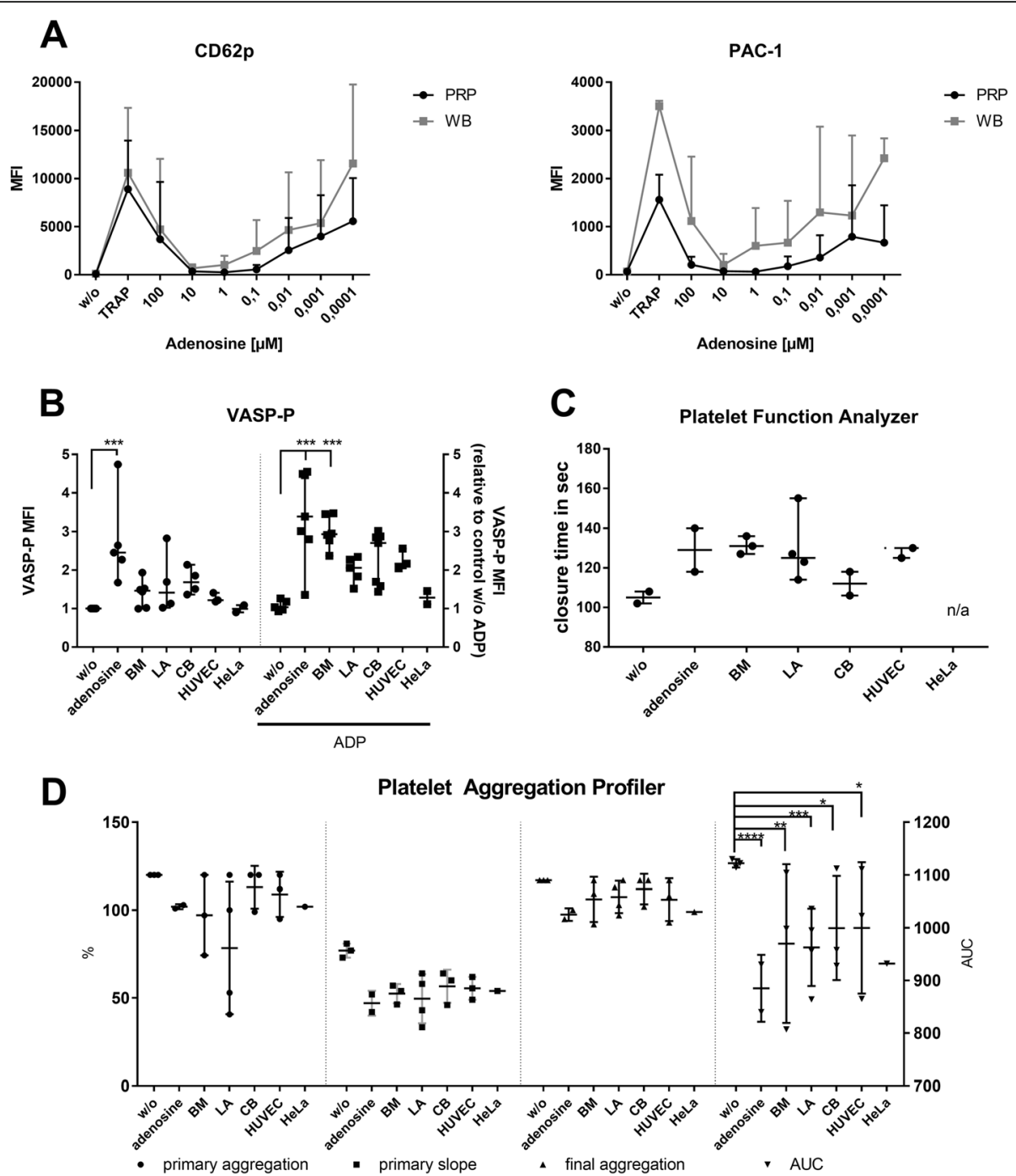

Fig. 6 Platelet function analyses. Platelet function analyses. a Dose-dependent effect of adenosine on platelet activation (MFI of CD62p and PAC$1, n=3)$. $\mathbf{b}$ Phosporylation state of vasodilator-stimulated phoshoprotein (VASP), VASP-P MFI levels c Closure time measured as time platelets need to close an ADP/collagen-coated aperture measured using PFA-100 device, comparing nontreated, adenosine and cell-cocultured whole blood. ${ }^{* * *} p<0.001$. $\mathbf{d}$ Platelet function assessed using light transmission aggregometry (platelet aggregation profiler). Aggregation cascade can be separated into primary aggregation and slope, final aggregation (all left $y$ axis) and area under the curve (AUC; right $y$ axis) assessing entire aggregation response. ${ }^{*} p \leq 0.05,{ }^{* *} p \leq 0.01,{ }^{* * *} p \leq 0.001,{ }^{* * * *} p \leq 0.0001$. ADP adenosine diphosphate, BM bone marrow, CB cord blood, HUVEC human umbilical vein endothelial cell, LA lipoaspirate, MFI mean fluorescence intensity, n/a not analyzed, PRP platelet-rich plasma, TRAP thrombin receptor activator for peptide, WB whole blood, w/o without

We identified the underlying mechanism to involve CD73-converted adenosine as summarized in Fig. 8. Activated platelets release ATP and ADP from their dense granules. Subsequent dephosphorylation of these agonists to the antagonists AMP by platelet CD39 and adenosine by MSC CD73 induces P1 receptor signaling to raise cAMP levels and VASP phosphorylation. This finally stops the activation cascade and reduces excessive platelet reactivity.

In fact, we confirmed that adenosine is produced in MSC-platelet cocultures at levels inhibitory for platelet function in PRP and whole blood. Using inhibitors of these enzymes and adenosine receptors, we verified the crucial role of CD73-converted adenosine. The CD39 inhibitor POM-1 had only minor effects on phosphate and adenosine release but inhibited platelet activation per se, supporting the CD39 expression and activity in platelets. In contrast, blockade of $\mathrm{CD} 73$ by AMP-CP resulted in a compensation of MSC inhibitory effects along with a significant inhibition of AMP hydrolysis to phosphate and adenosine, correlating receptor expression to function. Caffeine, an unspecific adenosine P1 receptor blocker, and $\mathrm{SCH}$ 58261, a specific A2AR antagonist, reduced the inhibitory effect of MSCs and adenosine. The fact 
TFPI1
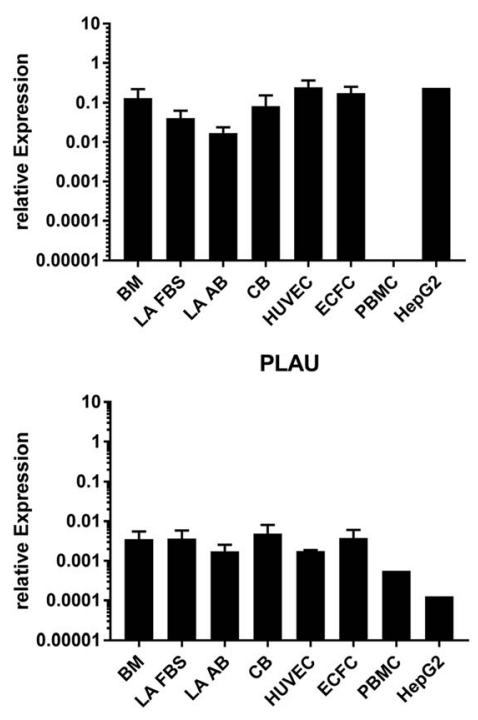

uPAR

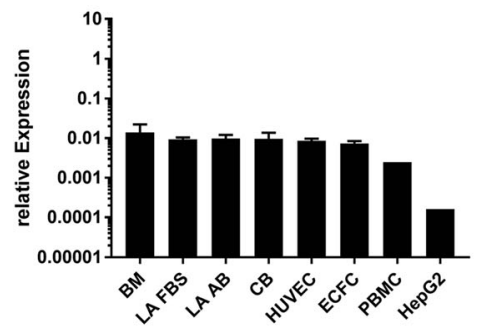

PAI

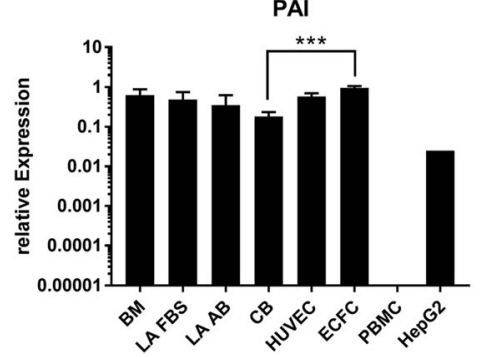

TFPI2
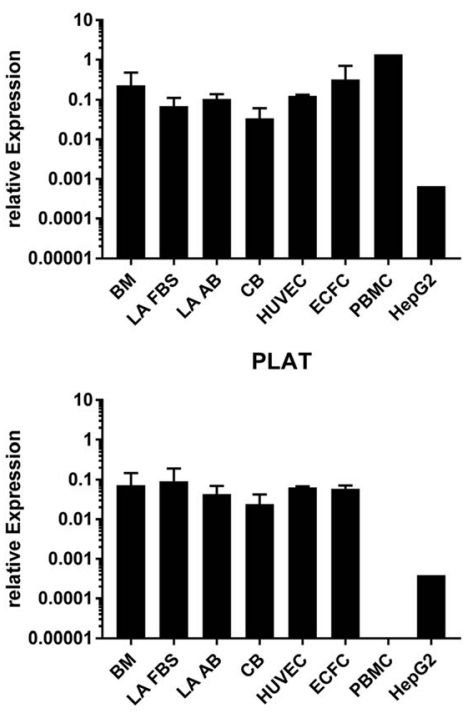

PLG

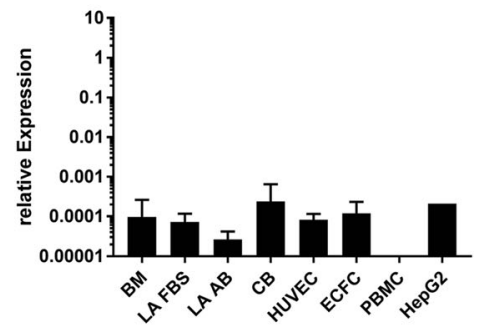

TF

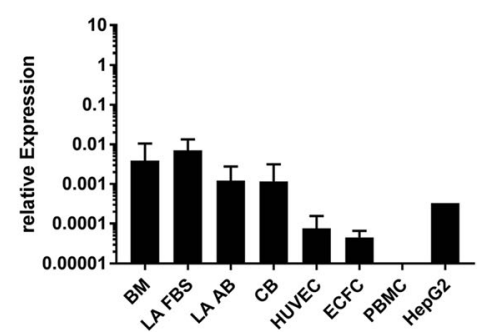

Fig. 7 RT-qPCR analysis of prothrombogenic and antithrombogenic genes. Gene expression analyzed in $B M n=3, L A F B S n=3$, LA human $A B-$ serum $n=2$, CB $n=3$, HUVECs $n=3$, ECFCs $n=3$, PBMCs, HepG2 cells and HeLa cells each $n=1 .{ }^{* *} p<0.001$. BM bone marrow, CB cord blood, ECFC endothelial colony forming cell, FBS fetal bovine serum, HUVEC human umbilical vein endothelial cell, LA lipoaspirate, PBMC peripheral blood mononuclear cell

that SCH 58261 had a stronger compensatory effect on adenosine than caffeine, but minor effects in MSC cocultures, suggests the involvement of further adenosine receptor subtypes, nucleotide processing enzymes or nucleoside transporters [31, 40, 43]. It is, however, beyond the scope of this study to fully dissect the cascade of purinergic signaling.

Recent studies have documented that MSC CD73-converted adenosine contributes to the immunomodulatory capacities of MSCs [37-40]. As in our study, CD39 and CD73 activity may be influenced by the tissue milieu (e.g. in cancer) and may require cooperation between different cell types [37, 40, 46].
We show that platelets express both CD39 and A2AR, but CD73 only weakly. In contrast, MSCs had low CD39 and low A2AR expression but high CD73 expression. The observed differences between BM-MSCs, LA-MSCs and CB-MSCs may relate to differences in nucleotide hydrolysis activity [32]. In contrast to our data, other authors detected CD39 expression in MSCs. Schuler et al. [40, 46] suggest that CD39 expression is largely influenced by the tissue source and activation state. Kerkelä et al. [37] observed CD39 expression only in BM-MSCs, but not in CB-MSCs. LA-MSCs have been tested negative for CD39 [47]. In addition, MSCs from different murine tissues have been shown to differ with respect to 


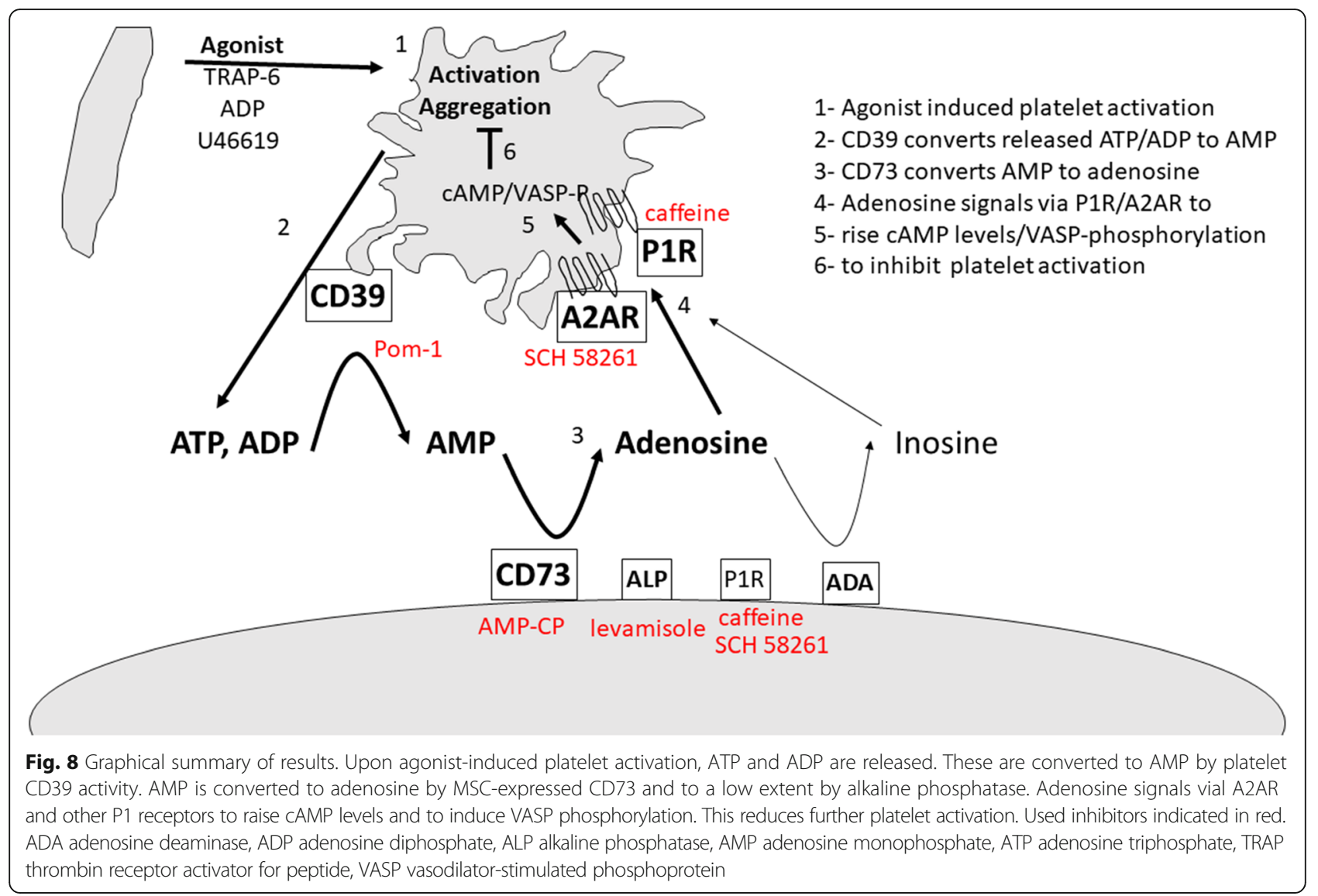

ectonucleotidase activity. Murine adipose tissue-derived MSCs had significantly higher ATP hydrolysis capacity than BM-MSCs, although the AMP hydrolysis activity was comparable. The authors concluded that MSCs exert tissue-specific roles in regulating the purinergic system [48]. Besides CD39, ectonucleotide pyrophosphatases/phosphodiesterases (E-NPPs) could be involved in AMP generation, as shown for HeLa cells and HUVECs [49].

Our data indicate that CD73 is the key enzyme involved in antithrombotic adenosine production. Strikingly, the enzymatic activity of HUVECs was low, despite high CD73 expression. Discrepant expression and activity data have been described and may be based on point mutations, splicing alterations or posttranslational modifications [50-53]. Other enzymes such as alkaline phosphatase could be involved in nucleotide metabolism [31]. ALP activity was detected at differing levels in HeLa cells and MSCs (highest in BM-MSCs, lower in LA-MSCs and low in both CB-MSCs and HUVECs). Using levamisole as an ALP inhibitor, the MSC inhibitory activity was reduced. ADA, which degrades adenosine to inosine, was also found to be active in all tested cells, with quite high activity in LA-MSCs.

Documenting that MSCs induce adenosine signaling, we verified that VASP phosphorylation was increased, indicating adenylate cyclase activity and increased cAMP levels by both MSCs and adenosine. Thus, both CD39-mediated ADP removal plus CD73-mediated adenosine production modulates platelet activation as summarized in Fig. 8.

Of high relevance for translation to the clinic, MSCs exerted their inhibitory effects not only in PRP, but also in whole blood. In whole blood, leukocytes and erythrocytes but also soluble enzymes add to purinergic signaling exerting CD39 and CD73 activity and removing adenosine by equlibrative nucleoside transporters, respectively $[34,46]$. Our data show that adenosine produced by MSCs can affect platelet activation, despite the presence of the other cells, to an extent measurable in diagnostic point-of-care tests.

We observed a common inhibitory activity of MSCs with similar effects on all markers and agonist stimulations. Only after U46619 stimulation did the inhibitory effect appear to be weaker. It might therefore be possible that the thromboxane-induced pathway of platelet activation is less impaired by MSCs. Another possibility is that U46619 may act directly on MSCs. Two reports indicate that U46619/thromboxane a(2) affects MSC differentiation, migration and proliferation $[54,55]$. 
Importantly, BM-MSCs and LA-MSCs had no effect on resting platelets. This fits data indicating that MSC-seeded nanofibrous scaffolds were protected from platelet adhesion and thrombus formation [21]. Only some batches of CB-MSCs induced activation marker expression in resting platelets, similar to the tested tumor cell line HeLa. The effect of CB-MSCs on resting platelets may indicate an increased thromboembolic risk associated with their application, or in a different setting, a beneficial hemostatic potential [13]. Expression of various prothrombotic and antithrombotic genes, however, was similar for the MSCs from different cellular sources. These data support our previous findings that CB-MSCs differ from BM-MSCs and LA-MSCs in several aspects, namely frequency, differentiation, immunomodulation, cell marker expression and size [23, 34]. Besides intrinsic heterogeneity of MSC preparations, $\mathrm{CB}$ appears to generate at least two distinct MSC-like populations $[23,56,57]$. It is a matter of future studies to correlate heterogeneity to function.

Interestingly, conditioned MSC medium had no impact on resting platelets or on the degree of agonist-induced activation, in contrast to previous reports suggesting a releasable ADPase activity in polymorphonuclear leukocytes [58]. We conclude that there is no significant production of any soluble platelet-affecting substances under standard cell culture conditions, but that the inhibitory activity is exerted by cell-bound CD73, which metabolizes extracellular AMP to adenosine.

As our major goal is to ensure the safety of MSC infusions, it is imperative to understand the effects of MSCs on hemostasis after systemic infusion. Hemostasis is a multistep process involving vasoconstriction, platelet plug formation and coagulation, and finally fibrinolysis. MSC involvement has been evaluated previously, focusing on individual steps:

1. MSC conditioned media may promote vasodilation of pulmonary artery rings [59].

2. TF expression by MSCs may cause thromboembolism, preventable by use of, or example, heparin [12, 15].

3. Fibrinolytic activity may regulate migration and wound healing $[60,61]$.

As a fourth mechanism by which MSCs can influence hemostasis, this study shows that MSCs prevent excessive platelet responsiveness by CD73-converted adenosine.

The strength of this study is the combination of a translationally relevant issue with an important basic research question about the underlying mechanism. Our conclusions build on robust data based on a large number of MSC and platelet combinations, and MSCs from three different tissues plus two control cell types, with the effects demonstrated in both PRP and whole blood and using a variety of different test systems. The work opens some new lines of inquiry and questions to be answered in subsequent studies, including tissue-specific CD73 expression/activity and the interplay of other cell-bound and soluble nucleotide processing factors.

\section{Conclusions}

Our study documents that MSCs do not induce platelet activation and thereby thrombus formation, but rather actively inhibit platelet activation by a CD73 activity generating antithrombotic adenosine. CB-MSCs show batch-dependent differences. Since CD73 activity has been further linked to tissue barrier function, adaptation to ischemic conditions/hypoxia and inflammation, this mechanism may contribute to the tissue-protective mode of action of MSCs.

\section{Additional files}

\begin{abstract}
Additional file 1: Table S1. Primer and probes used for RT-qPCR analysis. (DOCX $20 \mathrm{~kb}$ )

Additional file 2: Figure S1. Effect of MSCs on platelet adhesion and aggregation under shear flow conditions. To assess effect of MSCs on platelet activation under shear flow conditions, we performed microfluidic experiments using a pneumatically driven channel system (BioFlux, San Francisco, CA, USA) mounted on an inverted microscope capable of live cell reflectance interference contrast microscopy (RICM) as described previously [31]. Briefly, channels were coated with $10 \mu \mathrm{g} / \mathrm{cm}^{2}$ fibronectin (from human plasma F2006; Sigma Aldrich, St. Louis, MO, USA). The coated channels were filled with $300 \mu$ l of native whole blood with and without $1.5 \times 10^{5}$ BM-MSCs upon hematocrit adjustment and perfused with a constant shear stress of $5 \mathrm{dyne} / \mathrm{cm}^{2}$. At indicated points in time, RICM photographs of channel footprints were taken and analyzed by counting the number of adherent/aggregated platelets. BM-MSCs $n=3$. (TIF $1135 \mathrm{~kb}$ )
\end{abstract}

Additional file 3: Figure S2. Effect of MSCs on resting and agonistinduced platelet activation in impedance aggregometry. Impedance aggregometry experiments conducted using Multiplate ${ }^{\circledR}$ analyzer (Roche Diagnostics, Mannheim, Germany) [31]. Before stimulation, hirudinized whole blood samples were preincubated with respective cells or CM for 10 min, a 7-min phase outside the device followed by 3 min incubation in the aggregometer at $36^{\circ} \mathrm{C}$ under stirring. Then $3.3 \mu \mathrm{M}$ ADP or $6.7 \mu \mathrm{M}$ TRAP- 6 was added for platelet stimulation. Aggregation assessed for 6 min and determined as area under the curve (AUC). Whole blood incubated with two different concentrations of MSCs, HUVECs or HeLa cells. Then $5 \mu \mathrm{M}$ ADP or TRAP- 6 was added to stimulate platelets and impedance was measured. AUC values normalized to respective control without cells. $n=2-7$. (TIF $784 \mathrm{~kb}$ )

Additional file 4: Figure S3. Effect of MSCs on aggregation and thrombus formation. To assess aggregation and thrombus formation, fluorescence microscopy experiments were performed. To visualize platelets, PRP prestained for 30 min with Calcein-AM $(1 \mu \mathrm{g} / \mathrm{ml}$; Merck, Darmstadt, Germany). PRP with/without respective cells added to 96-well plates. To observe a cell effect on unstimulated cells, phase-contrast and fluorescence pictures taken after $10 \mathrm{~min}$ (Axio Imager D1, Zeiss AG, Oberkochen, Germany, with AxioVision software). Platelets then stimulated with $5 \mu \mathrm{M}$ TRAP- 6 for 10 min until taking another series of pictures. Top row, phase contrast; bottom row, fluorescence microscopy. Representative pictures from $n=2-3$ experiments. A-D $5 \mu \mathrm{M}$ TRAP-6-stimulated platelets. A Platelets w/o other cells. Strong aggregation and thrombus formation visible. B Platelets and HeLa cells. Strong aggregation visible with 
fewer but bigger clots compared to platelets alone. C Platelets and CBMSCs. Small aggregates with many single platelets visible. D Platelets and BM-MSCs. No aggregation visible. E-H Resting platelets. E Platelets w/o other cells. No aggregation visible. F Platelets and HeLa cells. Strong platelet aggregation and clotting visible. However, no platelet/HeLa aggregates formed. G Platelets and CB-MSCs. No clotting appears, but platelets appear to have undergone morphological changes indicating activation and adhesion. $\mathbf{H}$ Platelets and BM-MSCs. Single platelets grouped around BM-MSCs without aggregation or any evidence for activation. I Platelet aggregate size. Photomicrographs in $\mathbf{A}-\mathbf{H}$ analyzed with respect to aggregate size using ImageJ ( $n=3$ biological replicates for MSCS and HUVECs, $n=3$ technical replicates for HeLa, different fields of vision analyzed). $\mathbf{J}$ Platelet binding to MSCs. Cells gated on FSC/SSC and assessed for CD41 positivity indicative of platelet binding. No CD41 positivity detectable in cocultures with unstimulated and stimulated platelets. Representative histograms, mean \pm SD CD41 positivity values given relative to $\mathrm{W} / \mathrm{o}$ platelet control from $n=3$ experiments (technical replicates for HeLa). (TIF $8302 \mathrm{~kb}$ )

Additional file 5: Figure S4. Effect of MSCs on platelet activation using different agonists and pathway inhibitors. A, B Effect of $10^{5}$ LA-MSCs $/ \mathrm{ml}$ on platelet activation after stimulation with different agonists ADP, TRAP6 and U46619 $(n=4)$. Expression of two different activation markers shown: A CD62P and B PAC-1 binding. ${ }^{*} p<0.05$. C, D Effect of AK4 and indomethacin on platelet inhibition by $5 \times 10^{5} \mathrm{BM}-\mathrm{MSCs} / \mathrm{ml}$. Platelets stimulated with TRAP-6. $x$ axis, PAC-1 fluorescence intensity; $y$, axis, platelet count. One of two experiments shown: C AK4 to block CD62P and D MSC preculture in indomethacin to block COX. (TIF $176 \mathrm{~kb}$ )

\section{Abbreviations}

A2AR: Adenosine 2A receptor; ADA: Adenosine deaminase; ADP: Adenosine diphosphate; ALP: Alkaline phosphatase; AMP: Adenosine monophosphate; AMP-CP: a,, -Methyleneadenosine 5'-diphosphate; ATP: Adenosine triphosphate; BM: Bone marrow; CB: Cord blood; CM: Conditioned medium; COX: Cyclooxygenase; CPDA: Citrate phosphate dextrose adenine; ESI: Electrospray ionization; FBS: Fetal bovine serum; HUVEC: Human umbilical vein endothelial cell; IBMIR: Instant blood-mediated inflammatory reaction; LA: Lipoaspirate; MFI: Mean fluorescence intensity; MRM: Multiple reaction monitoring; MSC: Mesenchymal stromal cell; PAR-1: Proteaseactivated receptor 1; PFA: Platelet function analyzer; POM-1: Sodium polyoxotungstate; RT-qPCR: Real-time quantitative PCR; TF: Tissue factor; TRAP-6: Thrombin receptor activator for peptide 6; VASP: Vasodilatorstimulated phosphoprotein

\section{Acknowledgements}

FK and GB-W acknowledge support from the Helmholtz Programme Biolnterfaces in Technology and Medicine (BIFTM) of the Karlsruhe Institute of Technology (KIT). The authors are indebted to Gabi Rink and Angelika Schedel for their excellent assistance in Multiplate experiments and Torsten Gloe for his valuable discussions. Thanks to Adriana Torres Crigna, Agnese Fiori and Kathryn Melzak for critical reading and native speaker corrections. The authors thank all donors for providing tissue and blood material. They also thank all colleagues from the German Red Cross Blood Donor Service for providing human serum and platelet lysate, and the stem cell laboratory for providing cord blood units. The authors would also like to thank Prof. Ilse Hofmann, DKFZ, Heidelberg, for providing HeLa cells. They acknowledge financial

support by Deutsche Forschungsgemeinschaft within the funding program Open Access Publishing, by the Baden-Württemberg Ministry of Science, Research and the Arts and by Ruprecht-Karls-Universität Heidelberg.

\section{Funding}

The project was supported by a grant from the Stiftung Transfusionsmedizin und Immunhämatologie to PN.

\section{Availability of data and materials}

Data supporting the findings of this study are available within the article and its supplementary information files.

\section{Authors' contributions}

PN contributed to conception and design, collection and/or assembly of data, data analysis and interpretation, manuscript writing and final approval of the manuscript. SE-H contributed to collection and/or assembly of data, data analysis and interpretation, and final approval of the manuscript. SU contributed to data analysis and interpretation, and final approval of the manuscript. HK contributed to conception and design, financial and administrative support, and final approval of the manuscript. VH, FK, GB-W and KJ contributed to collection and/or assembly of data, data analysis and interpretation, and final approval of the manuscript. HS and PW contributed to provision of study material or patients and final approval of the manuscript. PB contributed to conception and design, manuscript writing and final approval of the manuscript. KB contributed to conception and design, financial support, administrative support, collection and/or assembly of data, data analysis and interpretation, manuscript writing and final approval of the manuscript.

\section{Ethics approval and consent to participate}

Platelet donors were volunteer healthy persons giving informed consent, who had not been taking any platelet inhibiting medication for at least 2 weeks. The Mannheim Ethics Commission II confirmed that the regular blood donor questionnaire and informed consent documentation waives the need for ethical approval.

MSC experiments were approved by the Mannheim Ethics Commission II (vote numbers 2010-262 N-MA, 2009-210 N-MA, 49/05 and 48/05).

\section{Consent for publication}

Not applicable.

\section{Competing interests}

PW receives honoraria from and has membership on Advisory Boards for Sanofi-Aventis. The remaining authors declare that they have no competing interests.

\section{Publisher's Note}

Springer Nature remains neutral with regard to jurisdictional claims in published maps and institutional affiliations.

\section{Author details}

${ }^{1}$ Institute of Transfusion Medicine and Immunology, Medical Faculty Mannheim, Heidelberg University, German Red Cross Blood Donor Service Baden-Württemberg-Hessen, Friedrich-Ebert Straße 107, 68167 Mannheim, Germany. ${ }^{2}$ Flow Core Mannheim, Medical Faculty Mannheim, Heidelberg University, Mannheim, Germany. ${ }^{3}$ Center for Internal Medicine, University Medical Center Hamburg-Eppendorf, Hamburg, Germany. ${ }^{4}$ Experimental Dermatology, Medical Faculty Mannheim, Heidelberg University, Mannheim, Germany. ${ }^{5}$ Institute of Functional Interfaces, Karlsruhe Institute of Technology, Eggenstein-Leopoldshafen, Germany. ${ }^{\text {Institute for Clinical }}$ Chemistry, Medical Faculty Mannheim, Heidelberg University, Mannheim, Germany. ${ }^{7}$ Mannheim Clinic for Plastic Surgery, Mannheim, Germany.

Received: 9 March 2018 Revised: 8 June 2018 Accepted: 19 June 2018 Published online: 04 July 2018

\section{References}

1. Sharma RR, Pollock K, Hubel A, McKenna D. Mesenchymal stem or stromal cells: a review of clinical applications and manufacturing practices. Transfusion. 2014;54(5):1418-37.

2. Butler J, Epstein SE, Greene SJ, Quyyumi AA, Sikora S, Kim RJ, Anderson AS, Wilcox JE, Tankovich NI, Lipinski MJ, et al. Intravenous allogeneic mesenchymal stem cells for nonischemic cardiomyopathy: safety and efficacy results of a phase II-A randomized trial. Circ Res. 2017;120(2):332-40.

3. Panes J, Garcia-Olmo D, Van Assche G, Colombel JF, Reinisch W, Baumgart DC, Dignass A, Nachury M, Ferrante M, Kazemi-Shirazi L, et al. Expanded allogeneic adipose-derived mesenchymal stem cells (Cx601) for complex perianal fistulas in Crohn's disease: a phase 3 randomised, double-blind controlled trial. Lancet. 2016;388(10051):1281-90.

4. Lalu MM, Mclntyre L, Pugliese C, Fergusson D, Winston BW, Marshall JC, Granton J, Stewart DJ, Canadian Critical Care Trials Group. Safety of cell therapy with mesenchymal stromal cells (SafeCell): a systematic review and meta-analysis of clinical trials. PLoS One. 2012;7(10):e47559.

5. Vulliet PR, Greeley M, Halloran SM, MacDonald KA, Kittleson MD. Intracoronary arterial injection of mesenchymal stromal cells and microinfarction in dogs. Lancet. 2004;363(9411):783-4. 
6. Tatsumi K, Ohashi K, Matsubara Y, Kohori A, Ohno T, Kakidachi H, Horii A Kanegae K, Utoh R, Iwata $T$, et al. Tissue factor triggers procoagulation in transplanted mesenchymal stem cells leading to thromboembolism. Biochem Biophys Res Commun. 2013;431(2):203-9.

7. Furlani D, Ugurlucan M, Ong L, Bieback K, Pittermann E, Westien I, Wang W, Yerebakan C, Li W, Gaebel R, et al. Is the intravascular administration of mesenchymal stem cells safe? Mesenchymal stem cells and intravital microscopy. Microvasc Res. 2009;77(3):370-6.

8. Lee RH, Pulin AA, Seo MJ, Kota DJ, Ylostalo J, Larson BL, Semprun-Prieto L, Delafontaine P, Prockop DJ. Intravenous hMSCs improve myocardial infarction in mice because cells embolized in lung are activated to secrete the anti-inflammatory protein TSG-6. Cell Stem Cell. 2009;5(1):54-63.

9. Shiratsuki S, Terai S, Murata Y, Takami T, Yamamoto N, Fujisawa K, Burganova G, Quintanilha LF, Sakaida I. Enhanced survival of mice infused with bone marrow-derived as compared with adipose-derived mesenchymal stem cells. Hepatol Res. 2015;45(13):1353-9.

10. Cyranoski D. Korean deaths spark inquiry. Nature. 2010;468(7323):485.

11. Cui LL, Kerkelä E, Bakreen A, Nitzsche F, Andrzejewska A, Nowakowski A, Janowski M, Walczak P, Boltze J, Lukomska B, et al. The cerebral embolism evoked by intra-arterial delivery of allogeneic bone marrow mesenchymal stem cells in rats is related to cell dose and infusion velocity. Stem Cell Res Ther. 2015;6:11.

12. Gleeson BM, Martin K, Ali MT, Kumar AH, Pillai MG, Kumar SP, O'Sullivan JF, Whelan D, Stocca A, Khider W, et al. Bone marrow-derived mesenchymal stem cells have innate procoagulant activity and cause microvascular obstruction following intracoronary delivery: amelioration by antithrombin therapy. Stem Cells. 2015;33(9):2726-37.

13. Moll G, Ignatowicz L, Catar R, Luecht C, Sadeghi B, Hamad O, Jungebluth $P$, Dragun D, Schmidtchen A, Ringden O. Different procoagulant activity of therapeutic mesenchymal stromal cells derived from bone marrow and placental decidua. Stem Cells Dev. 2015;24(19):2269-79.

14. Oeller M, Laner-Plamberger S, Hochmann S, Ketterl N, Feichtner M, Brachtl G, Hochreiter A, Scharler C, Bieler L, Romanelli P, et al. Selection of tissue factor-deficient cell transplants as a novel strategy for improving hemocompatibility of human bone marrow stromal cells. Theranostics. 2018;8(5):1421-34

15. Stephenne X, Nicastro E, Eeckhoudt S, Hermans C, Nyabi O, Lombard C, Najimi M, Sokal E. Bivalirudin in combination with heparin to control mesenchymal cell procoagulant activity. PLoS One. 2012;7(8):e42819.

16. Moll G, Rasmusson-Duprez I, von Bahr L, Connolly-Andersen AM, Elgue G, Funke L, Hamad OA, Lonnies H, Magnusson PU, Sanchez J, et al. Are therapeutic human mesenchymal stromal cells compatible with human blood? Stem Cells. 2012;30(7):1565-74.

17. Liao L, Shi B, Chang H, Su X, Zhang L, Bi C, Shuai Y, Du X, Deng Z, Jin Y. Heparin improves BMSC cell therapy: anticoagulant treatment by heparin improves the safety and therapeutic effect of bone marrow-derived mesenchymal stem cell cytotherapy. Theranostics. 2017;7(1):106-16.

18. Wegmeyer H, Broske AM, Leddin M, Kuentzer K, Nisslbeck AK, Hupfeld J, Wiechmann K, Kuhlen J, von Schwerin C, Stein C, et al. Mesenchymal stromal cell characteristics vary depending on their origin. Stem Cells Dev. 2013;22(19):2606-18

19. Christy BA, Herzig MC, Montgomery RK, Delavan C, Bynum JA, Reddoch KM, Cap AP. Procoagulant activity of human mesenchymal stem cells. J Trauma Acute Care Surg. 2017:83(1 Suppl 1):S164-9.

20. Wang F, Li Z, Guan J. Fabrication of mesenchymal stem cells-integrated vascular constructs mimicking multiple properties of the native blood vessels. J Biomater Sci Polym Ed. 2013;24(7):769-83.

21. Hashi CK, Zhu Y, Yang GY, Young WL, Hsiao BS, Wang K, Chu B, Li S. Antithrombogenic property of bone marrow mesenchymal stem cells in nanofibrous vascular grafts. Proc Natl Acad Sci U S A. 2007;104(29): 11915-20.

22. Bieback K, Vinci M, Elvers-Hornung S, Bartol A, Gloe T, Czabanka M, Kluter H, Augustin $H$, Vajkoczy P. Recruitment of human cord blood-derived endothelial colony-forming cells to sites of tumor angiogenesis. Cytotherapy. 2013;15(6):726-39.

23. Kern S, Eichler H, Stoeve J, Kluter H, Bieback K. Comparative analysis of mesenchymal stem cells from bone marrow, umbilical cord blood, or adipose tissue. Stem Cells. 2006:24(5):1294-301.

24. Durante W, Kroll MH, Vanhoutte PM, Schafer Al. Endothelium-derived relaxing factor inhibits thrombin-induced platelet aggregation by inhibiting platelet phospholipase C. Blood. 1992;79(1):110-6.
25. Goerge T, Kleineruschkamp F, Barg A, Schnaeker EM, Huck V, Schneider MF, Steinhoff M, Schneider SW. Microfluidic reveals generation of platelet-strings on tumor-activated endothelium. Thromb Haemost. 2007;98(2):283-6.

26. van Velzen JF, Laros-van Gorkom BA, Pop GA, van Heerde WL. Multicolor flow cytometry for evaluation of platelet surface antigens and activation markers. Thromb Res. 2012;130(1):92-8.

27. Abou-Saleh H, Hachem A, Yacoub D, Gillis MA, Merhi Y. Endothelial progenitor cells inhibit platelet function in a P-selectin-dependent manner. J Transl Med. 2015;13:142.

28. Abou-Saleh H, Yacoub D, Theoret JF, Gillis MA, Neagoe PE, Labarthe B, Theroux P, Sirois MG, Tabrizian M, Thorin E, et al. Endothelial progenitor cells bind and inhibit platelet function and thrombus formation. Circulation. 2009;120(22):2230-9.

29. Fuentes E, Palomo I. Extracellular ATP metabolism on vascular endothelial cells: a pathway with pro-thrombotic and anti-thrombotic molecules. Vasc Pharmacol. 2015;75:1-6.

30. Glenn J, lyu DE, White A, Fox S, Heptinstall S. Adenosine derived from ADP can contribute to inhibition of platelet aggregation in the presence of a P2Y12 antagonist. J Thromb Haemost. 2011;9:728.

31. Jackson EK, Cheng DM, Verrier JD, Janesko-Feldman K, Kochanek PM. Interactive roles of CD73 and tissue nonspecific alkaline phosphatase in the renal vascular metabolism of 5'-AMP. Am J Physiol Renal Physiol. 2014; 307(6):F680-5.

32. Naasani LIS, Rodrigues C, de Campos RP, Beckenkamp LR, Iser IC, Bertoni APS, Wink MR. Extracellular nucleotide hydrolysis in dermal and limbal mesenchymal stem cells: a source of adenosine production. J Cell Biochem. 2017;118(8):2430-42.

33. Glenn JR, Dovlatova N, White AE, Dhillon K, Heptinstall S, Fox SC. VASPFix' for measurement of VASP phosphorylation in platelets and for monitoring effects of P2Y(12) antagonists. Thromb Haemost. 2014;111(3):539-48.

34. Karagianni M, Brinkmann I, Kinzebach S, Grassl M, Weiss C, Bugert P, Bieback K. A comparative analysis of the adipogenic potential in human mesenchymal stromal cells from cord blood and other sources. Cytotherapy. 2013;15(1):76-88.

35. Bieback K, Hecker A, Schlechter T, Hofmann I, Brousos N, Redmer T, Besser D, Kluter H, Muller AM, Becker M. Replicative aging and differentiation potential of human adipose tissue-derived mesenchymal stromal cells expanded in pooled human or fetal bovine serum. Cytotherapy. 2012;14(5): $570-83$.

36. Bieback K, Hecker A, Kocaomer A, Lannert H, Schallmoser K, Strunk D, Kluter H. Human alternatives to fetal bovine serum for the expansion of mesenchymal stromal cells from bone marrow. Stem Cells. 2009;27(9):2331-41.

37. Kerkelä E, Laitinen A, Rabina J, Valkonen S, Takatalo M, Larjo A, Veijola J, Lampinen M, Siljander $P$, Lehenkari $P$, et al. Adenosinergic immunosuppression by human mesenchymal stromal cells requires cooperation with T cells. Stem Cells. 2016;34(3):781-90.

38. Saldanha-Araujo F, Ferreira Fl, Palma PV, Araujo AG, Queiroz RH, Covas DT, Zago MA, Panepucci RA. Mesenchymal stromal cells up-regulate CD39 and increase adenosine production to suppress activated T-lymphocytes. Stem Cell Res. 2011;7(1):66-74.

39. Sattler C, Steinsdoerfer M, Offers M, Fischer E, Schierl R, Heseler K, Daubener W, Seissler J. Inhibition of T-cell proliferation by murine multipotent mesenchymal stromal cells is mediated by CD39 expression and adenosine generation. Cell Transplant. 2011;20(8):1221-30.

40. Schuler PJ, Brandau S. Adenosine producing mesenchymal stem cells. Stem Cells. 2017;35(6):1647-8

41. Johnston-Cox HA, Yang D, Ravid K. Physiological implications of adenosine receptor-mediated platelet aggregation. J Cell Physiol. 2011;226(1):46-51.

42. Soslau G, Youngprapakorn D. A possible dual physiological role of extracellular ATP in the modulation of platelet aggregation. Biochim Biophys Acta. 1997;1355(2):131-40.

43. Scarfi S. Purinergic receptors and nucleotide processing ectoenzymes: their roles in regulating mesenchymal stem cell functions. World J Stem Cells. 2014;6(2):153-62.

44. Iyú D, Glenn JR, White AE, Fox SC, Heptinstall S. Adenosine derived from ADP can contribute to inhibition of platelet aggregation in the presence of a P2Y(12) antagonist. Arterioscler Thromb Vasc Biol. 2011;31(2):416-22.

45. Paniccia R, Priora R, Liotta AA, Abbate R. Platelet function tests: a comparative review. Vasc Health Risk Manag. 2015;11:133-48.

46. Schuler PJ, Westerkamp AM, Kansy BA, Bruderek K, Dissmann PA, Dumitru CA, Lang S, Jackson EK, Brandau S. Adenosine metabolism of human 
mesenchymal stromal cells isolated from patients with head and neck squamous cell carcinoma. Immunobiology. 2017;222(1):66-74.

47. Raposio E, Bonomini S, Calderazzi F. Isolation of autologous adipose tissuederived mesenchymal stem cells for bone repair. Orthop Traumatol Surg Res. 2016;102(7):909-12.

48. Iser IC, Bracco PA, Goncalves CEl, Zanin RF, Nardi NB, Lenz G, Battastini AMO, Wink MR. Mesenchymal stem cells from different murine tissues have differential capacity to metabolize extracellular nucleotides. J Cell Biochem. 2014;115(10):1673-82.

49. Gendaszewska-Darmach E, Maszewska M, Zaklos M, Koziolkiewicz M. Degradation of extracellular nucleotides and their analogs in HeLa and HUVEC cell cultures. Acta Biochim Pol. 2003;50(4):973-84.

50. Christensen LD. CD73 (ecto-5'-nucleotidase) on blood mononuclear cells. Regulation of ecto-5'-nucleotidase activity and antigenic heterogeneity of CD73 on blood mononuclear cells from healthy donors and from patients with immunodeficiency. APMIS Suppl. 1997;73:1-28.

51. Snider NT, Altshuler PJ, Wan S, Welling TH, Cavalcoli J, Omary MB. Alternative splicing of human NT5E in cirrhosis and hepatocellular carcinoma produces a negative regulator of ecto-5'-nucleotidase (CD73). Mol Biol Cell. 2014;25(25):4024-33.

52. Botta Gordon-Smith S, Ursu S, Eaton S, Moncrieffe H, Wedderburn LR. Correlation of low CD73 expression on synovial lymphocytes with reduced adenosine generation and higher disease severity in juvenile idiopathic arthritis. Arthritis Rheumatol. 2015;67(2):545-54

53. Christensen LD. No correlation between CD73 expression and ecto-5'nucleotidase activity on blood mononuclear cells in vitro. Evidence of CD73 (ecto-5'-nucleotidase) on blood mononuclear cells with distinct antigenic properties. APMIS. 1996;104(2):126-34.

54. Kim MR, Jeon ES, Kim YM, Lee JS, Kim JH. Thromboxane a(2) induces differentiation of human mesenchymal stem cells to smooth muscle-like cells. Stem Cells. 2009;27(1):191-9.

55. Yun DH, Song HY, Lee MJ, Kim MR, Kim MY, Lee JS, Kim JH. Thromboxane a(2) modulates migration, proliferation, and differentiation of adipose tissuederived mesenchymal stem cells. Exp Mol Med. 2009;41(1):17-24.

56. Bieback K, Kern S, Kluter H, Eichler H. Critical parameters for the isolation of mesenchymal stem cells from umbilical cord blood. Stem Cells. 2004;22(4): 625-34

57. Chang YJ, Tseng CP, Hsu LF, Hsieh TB, Hwang SM. Characterization of two populations of mesenchymal progenitor cells in umbilical cord blood. Cell Biol Int. 2006;30(6):495-9.

58. Zatta A, Pandolfo L, Caparrotta L, Prosdocimi M, Dejana E, Delmaschio A. Platelet-aggregation induced by the endoperoxide analogue U46619 is inhibited by polymorphonuclear leukocyte ADPase activity. Arterioscler Thromb. 1993:13(5):696-701.

59. Patel KM, Crisostomo P, Lahm T, Markel T, Herring C, Wang M, Meldrum KK, Lillemoe KD, Meldrum DR. Mesenchymal stem cells attenuate hypoxic pulmonary vasoconstriction by a paracrine mechanism. J Surg Res. 2007 143(2):281-5.

60. Heissig B, Dhahri D, Eiamboonsert S, Salama Y, Shimazu H, Munakata S, Hattori K. Role of mesenchymal stem cell-derived fibrinolytic factor in tissue regeneration and cancer progression. Cell Mol Life Sci. 2015;72(24):4759-70.

61. Neuss S, Schneider RKM, Tietze L, Knuchel R, Jahnen-Dechent W. Secretion of fibrinolytic enzymes facilitates human mesenchymal stem cell invasion into fibrin clots. Cells Tissues Organs. 2010;191(1):36-46.

\section{Ready to submit your research? Choose BMC and benefit from:}

- fast, convenient online submission

- thorough peer review by experienced researchers in your field

- rapid publication on acceptance

- support for research data, including large and complex data types

- gold Open Access which fosters wider collaboration and increased citations

- maximum visibility for your research: over $100 \mathrm{M}$ website views per year

At BMC, research is always in progress.

Learn more biomedcentral.com/submissions 